\title{
Desempenho de Fórmulas de Tempo de Concentração em Bacias Urbanas e Rurais
}

\author{
André Luiz Lopes da Silveira \\ Instituto de Pesquisas Hidráulicas - UFRGS \\ Porto Alegre, RS - andre@iph.ufrgs.br
}

Recebido: 30/03/04 revisado: 16/12/04 aceito: 03/03/05

\begin{abstract}
RESUMO
O tempo de concentração é um dos tempos de resposta da bacia hidrográfica mais utilizados no cálculo de chuvas e hidrogramas de projeto. Paradoxalmente, é um parâmetro hidrológico difícil de ser estabelecido com critério pelos projetistas porque há pouca informação sobre a aplicabilidade das diversas fórmulas empíricas disponíveis. É verdade que Kibler (1982) e McCuen et al (1984) são exemplos de fontes bibliográficas importantes que esclarecem vários aspectos sobre origem, uso e aplicabilidade de fórmulas empíricas de tempo de concentração, entretanto paira alguma dúvida sobre o desempenho absoluto e comparativo dessas fórmulas, ainda mais para os que consultam bibliografia em português, apesar do trabalho referencial de Porto (1995).

Esta situação motivou a realização do presente artigo com o objetivo de avaliar o erro de 23 fórmulas de tempo de concentração, incluindo aquelas mais encontradas na bibliografia técnica brasileira. Buscou-se confrontar as informações disponíveis sobre a origem das fórmulas e limitações teóricas, com o desempenho obtido em aplicações a bacias urbanas e rurais com dados observados. Vários resultados mostraram que é possível o uso de fórmulas de tempo de concentração para uma faixa de áreas de bacias muito superior às usadas em sua calibração, sobretudo em bacias rurais. No caso de bacias urbanas, as fórmulas com melhor desempenho mostraram uma faixa de erro maior do que as correspondentes em bacias rurais. $O$ estudo não objetivou fazer um "ranking" de todas as fórmulas, mas fornecer indicadores para uma escolha consciente caso a caso.
\end{abstract}

Palavras -chave : tempo de concentração, hidrograma, cheias, Kirpich, bacias urbanas, bacias rurais

\section{INTRODUCÃ̃O}

O tempo de concentração é um parâmetro hidrológico que surge da hipótese que a bacia hidrográfica responde como sistema linear para o escoamento superficial direto. Decorre desta hipótese a definição de tempo de concentração como o tempo necessário para que toda a bacia esteja contribuindo na seção de saída. Nesta condição hipotética de resposta linear da bacia o tempo de concentração é o tempo de equilíbrio quando se estabelece o regime permanente entre uma chuva efetiva de intensidade constante e o escoamento superficial direto dela decorrente.

O escoamento superficial numa bacia real pode ser visto como a combinação dos efeitos de translação e armazenamento. O primeiro é geralmente considerado linear, mas o segundo não, pois o escoamento varia com a carga hidráulica e, por conseqüência, o tempo de concentração, diminui com o aumento da intensidade da chuva. Portanto, o conceito de tempo de concentração como parâ- metro hidrológico invariável exige a admissão de uma propagação de onda considerando um valor de referência constante para a intensidade da chuva.

O tempo de concentração, como parâmetro hidrológico invariável, pode ser definido como o tempo necessário para uma gota d'água caminhar superficialmente do ponto mais distante (em percurso hidráulico) da bacia até o seu exutório (McCuen et al, 1984). Uma avaliação deste tempo poderia ser feita pelo tempo decorrido entre o fim da chuva (tempo em que caíram as últimas gotas sobre todos os pontos da bacia, portanto incluindo o ponto mais distante) e o tempo de fim do escoamento superficial detectado no hidrograma (instante de chegada da gota do ponto mais distante). Em resumo, o tempo de concentração seria o tempo entre o fim da chuva efetiva e o fim do escoamento superficial direto. Como a última gota a chegar do ponto mais distante corresponde teoricamente a escoamentos de baixa magnitude o tempo de concentração definido como a diferença entre o fim da chuva e o fim do escoamento superficial tende a ser maior 
que o "verdadeiro" tempo de concentração que é influenciado pela propagação hidráulica com carga média maior.

Portanto há uma incerteza prática na definição do tempo de concentração que muitas vezes afeta a gênese das fórmulas de cálculo. Normalmente, as medidas ou observações do tempo de concentração, das mais sofisticadas (com traçadores diversos) às mais pragmáticas (via análise hietogramahidrograma ou somatória de tempos de trânsito), podem superestimar o tempo de concentração caso refiram-se ao escoamento superficial com baixa carga hidráulica.

O método da somatória de tempos de trânsito, ou método cinemático (Porto, 1995), estabelecido pelo Soil Conservation Service (SCS) dos EUA em 1969, é desta categoria, mas foi utilizado por McCuen et al (1984) como método de obtenção de valores "observados" de tempo de concentração.

Por outro lado, pode haver procedimentos de obtenção de tempos de concentração "observados" por análise de eventos chuva-vazão, sem critérios rigorosos de magnitude,

Apesar dessas incertezas, este estudo propõe-se a avaliar o desempenho de 23 fórmulas de tempo de concentração, com base em arquivos-teste de valores "observados" de tempo de concentração, por sua vez obtidos de tempos de retardo (lag times) disponíveis na literatura técnico-científica, que foram medidos por análise de hietogramas e hidrogramas. Naturalmente estes arquivos podem ser contestados na sua representatividade e precisão, mas se justificam pela dificuldade de obtenção de medidas reais do tempo de concentração. De qualquer forma está claro que este artigo tem suas conclusões estreitamente ligadas aos arquivos-teste utilizados, recomendando-se cautela no seu uso prático.

Desta forma, este artigo não entra no mérito da pertinência ou não do tempo de concentração como parâmetro de referência para estipulação de precipitações e vazões de projeto, assim o foco é exclusivamente voltado para seu cálculo.

Tempo de concentração e tempo de retardo Freqüentemente os tempos de concentração são estimados a partir de tempos de retardo. Os tempos de retardo geralmente são definidos como intervalos entre o centro de gravidade temporal da chuva e o respectivo centro de gravidade do hidrograma ou o instante do pico do hidrograma. Naturalmente, se é o tempo do pico ou do centro de gravidade temporal do hidrograma que é considerado, tem-se tempos de retardo diferentes.

Normalmente, tem-se como conceito mais usual de tempo de retardo aquele que considera como limite final o instante do centro de gravidade do hidrograma e não seu instante de pico. Quando se usa o conceito de tempo de retardo considerando o limite no tempo de pico do hidrograma, costumase referi-lo apenas como tempo de pico.

Com base no hidrograma unitário triangular do SCS o tempo de concentração é 1,417 vezes maior que o tempo de retardo e 1,67 vezes maior que o tempo de pico (McCuen et al, 1984).

\section{METODOLOGIA}

Este artigo propõe-se a avaliar o desempenho de 23 fórmulas de tempo de concentração, calculando seus erros com dados de dois arquivosteste, um de bacias rurais retirado de MOPU (1987) e outro de bacias urbanizadas montado com dados publicados por Schaake (1967) e Desbordes (1974). As fórmulas, os arquivos-teste e a forma de avaliação dos erros são apresentados a seguir.

\section{Fórmulas testadas}

As fórmulas de tempo de concentração testadas foram as da Tabela 1. Parte delas foi transformada a partir de fórmulas de tempo de retardo e tempo de pico. A ordem das fórmulas na Tabela 1 obedece aproximadamente a uma lógica de natureza e de áreas contribuintes que estão explícitas na Tabela 7 apresentada mais adiante.

A Tabela 1 uniformizou as unidades de medida, estando elas adaptadas para dar o tempo de concentração em horas. O comprimento L refere-se ao comprimento em $\mathrm{km}$ do rio , canal ou talvegue principal, ou o comprimento de percurso hidráulico e $\mathrm{S}$ a sua declividade média $\mathrm{em} \mathrm{m} / \mathrm{m}$. Nas informações dadas pelas fontes bibliográficas há, por vezes, alguma imprecisão sobre a natureza de L, pois para uma mesma fórmula pode-se encontrar $\mathrm{L}$ definido como comprimento do curso d'água principal ou como o percurso de escoamento do talvegue desde o divisor de águas. Analogamente, para a declividade $\mathrm{S}$ há uma incerteza de como deve ser calculada. Entretanto, pode-se afirmar com alguma certeza que, para as seguintes fórmulas, L deve ser contado desde a cabeceira e $\mathrm{S}$ avaliado pela razão entre o desnível máximo e o comprimento L do percurso : Izzard, Kerby-Hathaway, Onda Cinemática, FAA, Kirpich, SCS lag, Simas-Hawkins, Giandotti, Pasini, Ventura, DNOS e George Ribeiro. Para as fórmulas de Ven te Chow, Johnstone, Corps of Engineers e Picking L, normalmente é referido como o comprimento do curso d'água principal e S sua declividade média (sem menção ao modo de cálculo). Para as 
demais fórmulas, de aplicação urbana (Schaake, McCuen, Carter, Eagleson, Desbordes e Espey), L é basicamente o comprimento do coletor pluvial ou canal principal e $\mathrm{S}$ a sua declividade média.

Tabela 1 - Fórmulas de tempo de concentração testadas

\begin{tabular}{ll}
\hline Nome & Equação $(1)$ \\
\hline Izzard (2) & $\mathrm{T}_{\mathrm{c}}=85,5\left(\mathrm{i} / 36286+\mathrm{C}_{\mathrm{r}}\right) \mathrm{i}^{-0,667} \mathrm{~L}^{0,33} \mathrm{~S}^{-0,333}$ \\
Kerby-Hathaway (3) & $\mathrm{T}_{\mathrm{c}}=0,619 \mathrm{~N}^{0,47} \mathrm{~L}^{0,47} \mathrm{~S}^{-0,235}$ \\
Onda Cinem. (2) & $\mathrm{T}_{\mathrm{c}}=7,35 \mathrm{n}^{0,6} \mathrm{i}^{-0,4} \mathrm{~L}^{0,6} \mathrm{~S}^{-0,3}$ \\
FAA (2) & $\mathrm{T}_{\mathrm{c}}=0,37(1,1-\mathrm{C}) \mathrm{L}^{0,5} \mathrm{~S}^{-0,333}$ \\
Kirpich (2) & $\mathrm{T}_{\mathrm{c}}=0,0663 \mathrm{~L}^{0,77} \mathrm{~S}^{-0,385}$ \\
SCS Lag (2) & $\mathrm{T}_{\mathrm{c}}=0,057(1000 / \mathrm{CN}-9)^{0,7} \mathrm{~L}^{0,8} \mathrm{~S}^{-0,5}$ \\
Simas-Hawkins (4) & $\mathrm{T}_{\mathrm{c}}=0,322 \mathrm{~A}^{0,594} \mathrm{~L}^{-0,594} \mathrm{~S}^{-0,150} \mathrm{~S}_{\mathrm{scs}}{ }^{0,313}$ \\
Ven te Chow (5) & $\mathrm{T}_{\mathrm{c}}=0,160 \mathrm{~L}^{0,64} \mathrm{~S}^{-0,32}$ \\
Dooge (6) & $\mathrm{T}_{\mathrm{c}}=0,365 \mathrm{~A}^{0,41} \mathrm{~S}^{-0,17}$ \\
Johnstone (7) & $\mathrm{T}_{\mathrm{c}}=0,462 \mathrm{~L}^{0,5} \mathrm{~S}^{-0,25}$ \\
Corps Engineers (8) & $\mathrm{T}_{\mathrm{c}}=0,191 \mathrm{~L}^{0,76} \mathrm{~S}^{-0,19}$ \\
Giandotti (9) & $\mathrm{T}_{\mathrm{c}}=0,0559\left(4,0 \mathrm{~A}^{0,5}+1,5 \mathrm{~L}\right) \mathrm{L}^{-0,5} \mathrm{~S}^{-0,5}$ \\
Pasini (10) & $\mathrm{T}_{\mathrm{c}}=0,107 \mathrm{~A}^{0,333} \mathrm{~L}^{0,333} \mathrm{~S}^{-0,5}$ \\
Ventura (10) & $\mathrm{T}_{\mathrm{c}}=0,127 \mathrm{~A}^{0,5} \mathrm{~S}^{-0,5}$ \\
Picking (11) & $\mathrm{T}_{\mathrm{c}}=0,0883 \mathrm{~L}^{0,667} \mathrm{~S}^{-0,333}$ \\
DNOS (12) & $\mathrm{T}_{\mathrm{c}}=0,419 \mathrm{k}^{-1} \mathrm{~A}^{0,3} \mathrm{~L}^{0,2} \mathrm{~S}^{-0,4}$ \\
George Ribeiro (13) & $\mathrm{T}_{\mathrm{c}}=0,222(1,05-0,2 \mathrm{p})^{-1} \mathrm{LS}^{-0,04}$ \\
Schaake et al (14) & $\mathrm{T}_{\mathrm{c}}=0,0828 \mathrm{~L}^{0,24} \mathrm{~S}^{-0,16} \mathrm{~A}_{\mathrm{imp}}{ }^{-0,26}$ \\
McCuen et al (15) & $\mathrm{T}_{\mathrm{c}}=2,25 \mathrm{i}^{-0,7164} \mathrm{~L}^{0,5552} \mathrm{~S}^{-0,2070}$ \\
Carter (15) & $\mathrm{T}_{\mathrm{c}}=0,0977 \mathrm{~L}^{0,6} \mathrm{~S}^{-0,3}$ \\
Eagleson (15) & $\mathrm{T}_{\mathrm{c}}=0,274 n \mathrm{R}^{-0,67} \mathrm{LS}^{-0,5}$ \\
Desbordes (16) & $\mathrm{T}_{\mathrm{c}}=0,0869 \mathrm{~A}^{0,3039} \mathrm{~S}^{-0,3832} \mathrm{~A}_{\mathrm{imp}}{ }^{-0,4523}$ \\
Espey-Winslow (15) & $\mathrm{T}_{\mathrm{c}}=0,343 \phi \mathrm{L}^{0,29} \mathrm{~S}^{-0,145} \mathrm{~A}_{\text {imp }}^{-0,6}$ \\
\hline
\end{tabular}

(1) Tc (h), A ( $\left.\mathrm{km}^{2}\right), \mathrm{L}(\mathrm{km}), \mathrm{S}(\mathrm{m} / \mathrm{m})$; ver outras no texto

(2) Adaptada da Tc apresentada por Kibler (1982)

(3) Adaptada da Tc analisada por McCuen et al (1984)

(4) Tempo de retardo de Simas-Hawkins vezes 1,417

(5) Tempo de pico (MOPU, 1987) multiplicado por 1,67

(6) Adaptada da Tc da lista de Porto (1995)

(7) Adaptada da Tc analisada por USDA (1973)

(8) Tempo de retardo de MOPU (1987) vezes 1,417

(9) Adaptada da Tc apresentada por Correia (1983)

(10) Adaptada da Tc apresentada por Pfafstetter (1976)

(11) Adaptada da Tc apresentada por Pinto et al. (1976)

(12) Adaptada da Tc apresentada por Mello (1973)

(13) Adaptada da Tc apresentada por Garcez (1967)

(14) Adaptada da Tc apresentada por Shaaake et al (1967)

(15) Adaptada da Tc apresentada por McCuen et al (1984)

(16) Tempo de retardo de Desbordes multiplicado por 1,417

$\mathrm{Na}$ Tabela 1, a área A deve ser dada em $\mathrm{km}^{2}$, $\mathrm{A}_{\mathrm{imp}}$ é a fração de área impermeável e p (fórmula de George Ribeiro) é a fração de área com mata. Por- tanto, $A_{\text {imp }}$ e p variam entre 0 e 1 . A intensidade $\mathrm{i}$ da chuva é em $\mathrm{mm} / \mathrm{h}$, e a referência apontada por McCuen et al (1984) é $35 \mathrm{~mm} / \mathrm{h}$. Os parâmetros C e $\mathrm{CN}$, respectivamente, dos conhecidos métodos racional e SCS, são adimensionais. A rugosidade n é a de Manning. O fator k do DNOS tem tabela específica (Tabela 2).

Tabela 2 - Valores de k equação do DNOS (Mello, 1973)

\begin{tabular}{|c|c|}
\hline Características do terreno da bacia & $\mathrm{k}$ \\
\hline $\begin{array}{l}\text { Areno-argiloso, vegetação intensa, elevada } \\
\text { absorção }\end{array}$ & 2,0 \\
\hline $\begin{array}{l}\text { Comum, coberto de vegetação, absorção apre- } \\
\text { ciável }\end{array}$ & 3,0 \\
\hline $\begin{array}{l}\text { Argiloso, coberto de vegetação, absorção mé- } \\
\text { dia }\end{array}$ & 4,0 \\
\hline Com vegetação média, pouca absorção & 4,5 \\
\hline Em rocha, escassa vegetação, baixa absorção & 5,0 \\
\hline Rochoso, vegetação rala, reduzida absorção & 5,5 \\
\hline
\end{tabular}

O fator $\phi$ é o conhecido fator de condutância adimensional de Espey (Kibler, 1982). $\mathrm{S}_{\mathrm{scs}}$ (assim graficado para evitar confusão com o símbolo $\mathrm{S}$ adotado para a declividade) é o armazenamento do conhecido método SCS, dado por (25400/CN)-254, em mm. $\mathrm{O}$ coeficiente $\mathrm{C}_{\mathrm{r}}$ de Izzard pode ser avaliado pela Tabela 3 . $\mathrm{R}$ é o raio hidráulico $(\mathrm{m})$, na equação de Eagleson.

Tabela 3 - Valores de $\mathrm{C}_{\mathrm{r}}$ de Izzard (Pinto et al, 1976)

\begin{tabular}{ll}
\hline Superfície & $\mathrm{C}_{\mathrm{r}}$ \\
\hline Superfície asfáltica lisa & 0,007 \\
Pavimento de concreto & 0,012 \\
Pavimento de cascalho-betume & 0,017 \\
Gramado aparado & 0,046 \\
Leivas de grama densa & 0,060 \\
\hline
\end{tabular}

O fator $\mathrm{N}$ na equação de Kerby-Hathaway é a retardância que varia em função da rugosidade da superfície conforme a Tabela 4 encontrada em Wanielista et al. (1997). McCuen et al (1984) o interpreta como o mesmo coeficiente de rugosidade de Manning, mas, nas tabelas apresentadas por Wanielista et al. (1997) para N e n, há diferenças.

\section{Parâmetros para uso rural e urbano}

Para testar as fórmulas de tempo de concentração da Tabela 1 foi necessário fixar alguns parâ- 
metros de algumas fórmulas. A despeito das fórmulas já apresentarem na sua origem uma indicação de uso em bacias rurais ou urbanas elas foram preparadas indistintamente para uso especulativo em ambos tipos de bacias. A Tabela 5 apresenta os parâmetros que foram fixados.

Tabela 4 - Valores de $\mathbf{N}$ da equação de Kerby-Hathaway

\begin{tabular}{ll}
\hline Características da superfície & $\mathrm{N}$ \\
\hline Pavimento alisado & 0,02 \\
Cobertura com grama rala & 0,3 \\
Cobertura com grama média & 0,4 \\
Cobertura com grama espessa & 0,8 \\
\hline
\end{tabular}

Tabela 5 - Parâmetros fixos adotados nas fórmulas

\begin{tabular}{llll}
\hline Equação & Parâmetro & $\begin{array}{l}\text { Rural } \\
\text { Ur- } \\
\text { bana }\end{array}$ \\
\hline Izzard & $\mathrm{C}_{\mathrm{r}}$ & 0,06 & 0,012 \\
Kerby-Hathaway & $\mathrm{N}$ & 0,8 & 0,02 \\
Onda Cinemática / & & & \\
Eagleson & $\mathrm{n}$ & 0,030 & 0,016 \\
Onda Cinemática/McCuen & $\mathrm{i}(\mathrm{mm} / \mathrm{h})$ & 35 & 35 \\
FAA & $\mathrm{C}$ & 0,01 & 0,90 \\
SCS Lag/Simas-Hawkins & $\mathrm{CN}$ & 70 & 90 \\
DNOS & $\mathrm{k}$ & 3,0 & 5,0 \\
George Ribeiro & $\mathrm{p}$ & 0,50 & 0 \\
Schaake/Desbordes/Espey & $\mathrm{A}_{\text {imp }}$ & 0,01 & $\mathrm{obs}$ \\
Eagleson & $\mathrm{R}(\mathrm{m})$ & 0,20 & 0,02 \\
Espey-Winslow & $\phi$ & 1,0 & 0,3 \\
\hline
\end{tabular}

\section{Fontes bibliográficas das fórmulas}

As fontes bibliográficas principais consultadas para obtenção das fórmulas analisadas estão indicadas na Tabela 6. Na bibliografia do artigo, outras publicações são citadas e todas elas contribuíram, de fato, para se organizar as informações tratadas no presente artigo. Nas publicações consultadas podem ser encontradas as equações de tempo de concentração, retardo ou pico em versões originais ou com outras unidades de medida.

Diferenças ou erros nas fórmulas publicadas A equação de Izzard publicada por Pinto et al (1976) multiplica por C (método racional) a intensidade da precipitação, mas somente aquela com expoente fracionário, deixando de lado aquela do termo i/36286 que se soma a $\mathrm{C}_{\mathrm{r}}$. Aparentemente isto foi feito para garantir que somente a chuva efetiva fosse introduzida na fórmula, mas, o fazendo parcialmente, desequilibra a fórmula. Canedo (1989) e Prusky e Silva (1997) repetem o procedimento. Kibler (1982) e Wanielista et al (1997) não fazem essa modificação.

A fórmula de Kerby-Hathaway, assim chamada por McCuen et al (1984), é frequentemente referida apenas como equação de Kerby, como em Wanielista et al (1997). McCuen et al (1984) interpretam o coeficiente $\mathrm{N}$ como o fator de rugosidade de Manning, mas é comum ser chamado de coeficiente de retardância. Em tabelas apresentadas por Wanielista et al (1997) há discrepâncias entre os valores desse coeficiente $\mathrm{N}$ com a rugosidade de Manning, deixando crer que seus valores não são exatamente iguais para um mesmo tipo de superfície.

Nas fórmulas da Onda Cinemática, FAA, Kirpich e SCS lag não foram encontradas discrepâncias significativas na bibliografia consultada, apesar das diversas versões em função das unidades de medida escolhidas para as variáveis.

A equação original de Simas e Hawkins (1996) não explicita as variáveis A e L conforme apresenta-se na Tabela 1. O que ela utiliza é uma variável $\mathrm{W}$, representando a largura média da bacia dada pela razão $\mathrm{A} / \mathrm{L}$. O que foi feito no presente artigo foi restituir essa razão $\mathrm{A} / \mathrm{L}$, no lugar de $\mathrm{W}$, procurando-se dar um cunho mais homogêneo com as outras fórmulas, quase todas com o comprimento L explícito. A fórmula de Simas-Hawkins original refere-se ao tempo de retardo, e neste artigo multiplicou-se por 1,417 (fator sugerido por McCuen et al, 1984) para obter a correspondente fórmula de tempo de concentração.

A fórmula de Ven te Chow é originalmente uma fórmula de tempo de pico e as fontes bibliográficas consultadas que a publicaram corretamente foram DAEE (1978) e MOPU (1987), com as respectivas escolhas de unidades. Há problemas, talvez de impressão, naquela publicada por Pinto et al (1976), devendo ser evitada. Na publicação de Prusky e Silva (1997) a fórmula de tempo de pico de Ven te Chow é publicada como sendo uma fórmula de tempo de concentração, não tendo sido aplicado um fator corretivo para tal, assim seu uso subestima o Tc. No presente artigo foi aplicado o fator 1,67, conforme sugerido por McCuen et al, 1984

A equação de Dooge foi divulgada no Brasil por Porto (1995). No boletim técnico do USDA (1973) encontra-se a mesma fórmula, com outras unidades de medida, sem discrepâncias com a adaptação de Porto (1995). Entretanto, em Prusky e Silva (1997) há um erro de grafia (Dodge no lugar de 
Dooge) e uma indicação errônea da unidade da declividade $(\mathrm{m} / \mathrm{km}$ quando o certo seria $\mathrm{m} / \mathrm{m})$.

Tabela 6 - Principais fontes bibliográficas consultadas

\begin{tabular}{lll}
\hline Fórmula & Ano & Fontes Bibliográficas \\
\hline Izzard & 1946 & Pinto et al (1976) e Kibler (1982) \\
Kerby-Hathaway & 1959 & McCuen (1984), Wanielista (1997) \\
Onda Cinemática & 1963 & Porto (1995) e Kibler (1982) \\
FAA & 1970 & Porto (1995) e Kibler (1982) \\
Kirpich & 1940 & Porto (1995) e Kibler (1982) \\
SCS Lag & 1975 & Porto (1995) e Kibler (1982) \\
Simas-Hawkins & 1996 & Simas e Hawkins (1996) \\
Ven te Chow & 1962 & DAEE (1978) e MOPU (1987) \\
Dooge & 1956 & Porto (1995) e USDA (1973) \\
Johnstone & 1949 & Tucci (1998) e USDA (1973) \\
Corps Engineers & 1946 & Linsley (1967) e MOPU (1987) \\
Giandotti & 1940 & Correia (1983) e MOPU (1987) \\
Pasini & $(*)$ & Pfafstetter (1976) \\
Ventura & $(*)$ & Pfafstetter (1976) \\
Picking & $(*)$ & Pinto et al (1976) \\
DNOS & 1955 & Mello (1973) e Ribeiro (1955) \\
George Ribeiro & 1961 & Garcez (1967) e Ribeiro (1961) \\
Schaake et al & 1967 & Schaake et al (1967) \\
McCuen et al & 1984 & McCuen et al (1984) \\
Carter & 1961 & McCuen et al (1984) \\
Eagleson & 1962 & McCuen et al (1984) \\
Desbordes & 1974 & Desbordes (1974) \\
Espey-Winslow & 1966 & McCuen et al (1984) \\
\hline
\end{tabular}

(*) Informação não constante na bibliografia consultada

A fórmula do tempo de concentração de Johnstone é também encontrada no boletim técnico do USDA (1973), que foi a fonte utilizada por Tucci (1998) no seu livro. Entretanto, a fórmula apresentada adota, após adaptação de unidades de medida, um coeficiente 20,17 (Tc em minutos) quando o valor correto é 27,75 . Ela também não foi obtida na Escócia, mas com dados do rio Scotie (EUA).

A fórmula do Corps of Engineers teve como fonte básica a publicação espanhola do MOPU (1987), não tendo sido consultada nenhuma publicação original do US Corps of Engineers (EUA), por dificuldade de acesso. MOPU (1987) apresenta a fórmula do tempo de retardo do Corps of Engineers, simplificando-a ao substituir o comprimento do rio principal até próximo do centro de gravidade $\left(\mathrm{L}_{\mathrm{C}}\right)$ da bacia pelo equivalente à metade do comprimento total L desse rio. Assim a fórmula depende apenas de L e S. Na fórmula original o tempo de retardo é proporcional ao fator $\left(\mathrm{L}^{\mathrm{L}} \mathrm{L}_{\mathrm{C}}\right) / \mathrm{S}^{0,5}$ na potência 0,38. Linsley et al (1967) expõem esta proporcionalidade para diferentes fisiografias de bacias enquanto MOPU (1987) não faz esta distinção.

A fórmula de Giandotti, com base em buscas na internet italiana, está correta no texto consultado de Correia (1983). O termo do denominador da fórmula original é $0,8 \mathrm{H}^{0,5}$, onde $\mathrm{H}$ é o desnível do exutório até o ponto de altitude média da bacia. MOPU(1987) simplifica ao substituir H pela multiplicação de uma declividade por um comprimento. Entretanto, ao substituir H por LS incorreu em erro, pois seria mais lógico considerar $2 \mathrm{H}=\mathrm{LS}$, o desnível total. Esta última aproximação correta foi usada no presente artigo.

As outras fórmulas italianas, de Pasini e Ventura, foram divulgadas no Brasil por Pfafstetter (1976). Há uma pequena diferença no coeficiente da fórmula de Pasini (0,107 contra 0,108 da internet italiana) que é irrelevante.

Sobre a fórmula de Picking, a referência primária no Brasil parece ser a de Pinto et al (1976), que infelizmente não citou explicitamente a fonte e uma procura bibliográfica dessa fórmula em outras fontes revelou-se infrutífera.

Com respeito a fórmula do DNOS primeiramente encontrou-se somente a referência de Mello (1973), apesar de ser provavelmente uma fórmula freqüentemente utilizada em órgãos técnicos do Brasil, como atestam vários memoriais de cálculo do DAER/RS. Nenhuma referência sobre sua origem tinha sido encontrada pelo autor do presente artigo até que, ao pesquisar vários artigos de George Ribeiro na Revista do Clube de Engenharia, constatou-se sua autoria (Ribeiro, 1955). Foi a equação estabelecida por George Ribeiro antes daquela mais conhecida que leva seu nome.

A equação que leva o nome de George Ribeiro teve grande divulgação com o livro de Garcez (1967). Em capítulo de outro livro de grande aceitação, Canedo (1989) a utiliza, mas há um erro de impressão que atribui ao coeficiente de "p" o valor 2 , quando o correto é 0,2. Uma pesquisa nos exemplares da Revista do Clube de Engenharia atesta que a equação de George Ribeiro foi apresentada em 1961 (Ribeiro, 1961).

As demais fórmulas foram retiradas de fontes primárias, caso das fórmulas de Schaake et al (1967), Desbordes (1974), e McCuen et al (1984), sendo desta última fonte retiradas, sem consulta a outras fontes, as equações de Carter, Eagleson e Espey-Winslow 
Tabela 7 - Características das bacias-base das fórmulas

\begin{tabular}{|c|c|c|c|c|c|c|}
\hline Nome & Local & $\begin{array}{c}\mathrm{N}^{\circ} \\
\text { bacias }\end{array}$ & $\begin{array}{l}\text { Área } \\
\mathrm{km}^{2}\end{array}$ & $\begin{array}{l}\mathrm{S} \\
\% \\
\end{array}$ & $\begin{array}{c}\mathrm{L} \\
\mathrm{km}\end{array}$ & Tipo \\
\hline Izzard & EUA & - & - & $<4$ & $\begin{array}{c}<0,02 \\
2\end{array}$ & Parcela \\
\hline Kerby & EUA & - & $<0,05$ & $<1$ & $<0,37$ & Parcela \\
\hline O. Cin. & EUA & - & - & - & $<0,03$ & Parcela \\
\hline FAA & EUA & - & - & - & - & Parcela \\
\hline Kirpich & EUA & $6 / 7$ & $<0,45$ & $3 / 10$ & $<1,2$ & Rural \\
\hline SCS Lag & EUA & - & $<8,1$ & - & - & Rural \\
\hline Simas & EUA & 168 & $<15$ & - & - & Rural \\
\hline Chow & EUA & 20 & $1,1 / 19$ & - & - & Rural \\
\hline Dooge & Irlanda & 10 & $\begin{array}{c}140 / 9 \\
30\end{array}$ & - & - & Rural \\
\hline Johnst. & EUA & 19 & $\begin{array}{c}65 / 42 \\
00\end{array}$ & - & - & Rural \\
\hline C. Eng. & EUA & 25 & $<12000$ & $<14$ & $<257$ & Rural \\
\hline Giandotti & Itália & - & - & - & - & Rural \\
\hline Pasini & Itália & - & - & - & - & Rural \\
\hline Ventura & Itália & - & - & - & - & Rural \\
\hline Picking & - & - & - & - & - & Rural \\
\hline DNOS & EUA & 6 & $<0,45$ & $3 / 10$ & $<1,2$ & Rural \\
\hline G. Ribeiro & EUA/Índia & 8 & $<19000$ & $1 / 10$ & $<250$ & Rural \\
\hline Schaake & EUA & 19 & $<0,7$ & $<7$ & $<1,8$ & Urbana \\
\hline McCuen & EUA & 48 & $0,4-16$ & $<4$ & $<10$ & Urbana \\
\hline Carter & EUA & - & $<21$ & $<0,5$ & $<12$ & Urbana \\
\hline Eagleson & EUA & - & $<21$ & - & - & Urbana \\
\hline Desbordes & França & 21 & $<51$ & $<7$ & $<18$ & Urbana \\
\hline Espey & EUA & 17 & $<91$ & - & - & Urbana \\
\hline
\end{tabular}

(-) informação não disponível nas fontes bibliográficas

\section{Limites de origem das fórmulas}

As fórmulas de tempo de concentração foram estabelecidas ao longo do tempo basicamente por necessidades práticas de engenharia. A maioria guarda por isso um caráter altamente empírico e são essencialmente equações de regressão, obtidas com preceitos estatísticos precários. Algumas são hidráulicas teóricas ou experimentais (como as de Onda Cinemática, Izzard e Eagleson).

As variáveis explicativas que aparecem nas fórmulas de tempo de concentração referem-se basicamente a:

- Tamanho da bacia : os parâmetros mais comuns sendo o comprimento $\mathrm{L}$ do talvegue principal e a área A da bacia;

- Declividade : que reflete a quantidade de movimento do escoamento superficial, sendo normalmente utilizada a declividade $\mathrm{S}$ do talvegue principal;

- Rugosidade ou resistência ao escoamento : enquadram-se aqui os parâmetros de rugosidade (como o n de Manning, a retardância N de Hathaway, o CN do SCS ou o $\phi$ de Espey, por exemplo), e taxas de áreas impermeáveis e permeáveis, entre outros;

- Aporte d'água : uma intensidade padrão de chuva é o parâmetro mais comum, e o raio hidráulico (Eagleson) poderia ser enquadrado aqui.

O uso dessas variáveis explicativas não advém rigorosamente de uma teoria física para o tempo de concentração, mesmo sabendo-se que ele poderia ser explicado por uma razão de distância por velocidade, a distância podendo ser medida em mapas e a velocidade podendo ser referida a equações hidráulicas como as de Manning e Chèzy. Esta base "física" indicaria que o tempo de concentração 
seria proporcional ao fator $\mathrm{LS}^{-0,5}$. De fato, a grande maioria das fórmulas utiliza $\mathrm{L}$ e $\mathrm{S}$, no entanto, de maneira empírica.

Justamente por terem, em geral, um caráter empírico e prático, freqüentemente as fórmulas de tempo de concentração são apresentadas em textos técnicos e, até mesmo, acadêmicos, sem fazer referência a todas às suas condições de origem e, consequentemente, aos seus limites de aplicação. Quando a aplicação de uma fórmula viola essas condições de origem, a princípio seu uso poderia ser considerado abusivo, mas isto, muitas vezes, não é reconhecido, por haver um código de aceitação mútua entre projetistas e fiscais. Por outro lado é possível que uma fórmula, obtida com dados precários ou insuficientes, obtenha bons resultados, captando por acaso a realidade física do processo.

O uso repetido de equações de tempo de concentração, sem maiores critérios, a não ser o da tradição ou fama, dificulta a tarefa de um usuário mais cuidadoso, pois raramente são enfatizados os limites das equações ou se estão disponíveis estudos comparativos com base científica. É comum, em muitos casos, inclusive, que se percam informações básicas sobre a origem e limite presumidos de várias equações, ou que sejam extremamente difíceis de acessar.

Através da bibliografia consultada apontada na Tabela 6 e no fim do artigo, as informações acerca das fórmulas foram sintetizadas na Tabela 7. Pode-se observar, de imediato, que há muitas lacunas nessas informações. O problema básico é o difícil acesso às publicações originais que apresentaram os métodos e não há certeza de que nelas constem todas as informações.

A Tabela 7 reúne, em um primeiro grupo inicial, as fórmulas de parcelas de tamanho restrito. Compreende as fórmulas de Izzard, KerbyHathaway, Onda Cinemática e da FAA (Federal Aviation Agency dos EUA). Em um segundo grupo reúne as equações que foram comprovada ou presumidamente obtidas com dados de bacias rurais. Um subgrupo rural está ordenado segundo ordem crescente das áreas das bacias experimentais (Kirpich, SCS lag, Simas-Hawkins, Ven te Chow, Dooge, Johnstone e Corps of Engineers). O segundo subgrupo rural lista as fórmulas de Giandotti, Pasini, Ventura Picking, DNOS e George Ribeiro para as quais há pouca ou nenhuma informação experimental. Apresenta-se, em seguida, o terceiro grupo, o grupo das fórmulas urbanas que são oriundas de ajustes a dados de bacias experimentais urbanas, listadas pela ordem crescente das áreas das bacias experimentais.
A equação de Izzard foi desenvolvida nos EUA em experimentos de laboratório sobre escoamentos em superfícies de rodovias pavimentadas e não pavimentadas (Kibler, 1982). Em Chen e Wong (1990) consta a informação de que os experimentos de Izzard ocorreram em parcelas de 3,7 a 21,9 m, com declividades variando de 0,1 a $4,0 \%$, e intensidades de chuva entre 42 e $104 \mathrm{~mm} / \mathrm{h}$. Portanto a equação de Izzard é de micro-escala e sua extrapolação para bacias, mesmo as pequenas pode não dar bons resultados. Algo semelhante poderia ser dito sobre a aplicabilidade da fórmula de KerbyHathaway que também foi baseada provavelmente em experimentos em parcelas. A equação da Onda Cinemática também refere-se a escoamento em superfície plana pequena, decorrente, pela teoria, de uma chuva de intensidade constante. Apesar das restrições da micro-escala que também se poderia fazer, Porto (1995) a considera adequada para bacias muito pequenas em que o escoamento em superfície seja predominante.

Sobre a fórmula da FAA (EUA) é difícil encontrar alguma informação experimental, exceto que ela foi desenvolvida para drenagem de aeroportos (McCuen et al, 1984). Pode-se inferir que seu uso seria indicado em áreas de drenagem muito pequenas e com significativas taxas de impermeabilização. Isto explica sua possibilidade de extrapolação de uso para bacias urbanas, desde que não possuíssem áreas grandes, pois neste caso seria de se esperar uma tendência de subestimação do tempo de concentração pela desconsideração de efeitos de armazenamento.

Quanto ao grupo das equações de tempo de concentração rurais, com alguma informação experimental, a primeira a ser comentada é a equação de Kirpich. Na verdade há duas equações de Kirpich (McCuen et al, 1984), mas aquela de utilização muito comum no Brasil é a que foi obtida para o estado do Tennessee (EUA) com dados de apenas sete bacias rurais (Kibler, 1982). Vários autores mencionam apenas seis bacias rurais. Os dados resultaram dos experimentos de Ramser publicados em 1927 (Ribeiro, 1955). As bacias são muito pequenas (até 45 hectares) com declividades altas (3 a 10\%), por isso há pouco efeito de armazenamento, refletindo significativamente o tempo de escoamento laminar sobre superfícies (McCuen et al, 1984). Quando extrapola-se sua aplicação a bacias maiores é de se esperar obter tempos de concentração menores que os reais. Para aplicação em bacias urbanizadas onde o percurso é asfaltado (superfícies) ou em concreto (condutos e canais), existe ainda a recomendação de que o tempo de concentração seja multiplicado, 
respectivamente por 0,4 e 0,2 (Kibler, 1982). Entretanto, isto valeria se toda a bacia fosse equipada com sistema de drenagem e houvesse um alto grau de impermeabilização.

A equação de Tc oriunda do SCS lag tem robustez experimental pois foi obtida com base em dados de pequenas bacias rurais americanas (até 8 $\mathrm{km}^{2}$ ). Reflete basicamente o escoamento em superfícies de bacias não urbanizadas. Há possibilidade de adaptação para uso em bacias urbanizadas com aplicação de fatores redutores do tempo de concentração em função da impermeabilização e atendimento com rede pluvial. Tucci (1998) reproduz equações analíticas desses fatores que são dependentes do CN. De qualquer forma, no presente artigo, o $\mathrm{CN}$ teve de ser fixado globalmente (as bacias experimentais usadas não possuíam esse dado), assim os resultados obtidos não devem ser tomados com rigor.

Um dos estudos mais abrangentes sobre tempo de retardo, para bacias rurais até $15 \mathrm{~km}^{2}$, foi realizado nos EUA e publicado na internet por Simas e Hawkins (1996). Dados de 168 bacias foram utilizados e mostraram que as bacias tinham uma tendência para ter um tempo de retardo constante para grandes tempestades. Não foi constatada a tendência do tempo de concentração diminuir com maiores intensidades de chuva, conforme indicado em muitos estudos. Também não foi constatada nenhuma influência da chuva antecedente de 48 horas sobre os tempos de resposta da bacias. O tempo de concentração baseado no tempo de retardo de Simas-Hawkins (1996) é função de três variáveis explicativas : a largura média $\mathrm{W}$ da bacia $(\cong \mathrm{A} / \mathrm{L})$, a declividade $S$ (talvegue principal) e o armazenamento $S_{\text {scs }}$ do método SCS que depende do parâmetro CN. A exemplo dos testes com a fórmula do SCS lag, ao se fixar, no presente artigo, o parâmetro CN (não há essa informação individualizada nos dados dos arquivos-teste das bacias aqui empregadas) a fórmula de Simas-Hawkins não poderia ser avaliada efetivamente. Assim, seus resultados de desempenho, negativos ou positivos, não devem ser tomados com muita exigência.

Para uma gama semelhante de bacias ( 1 a $19 \mathrm{~km}^{2}$ ), baseada nos dados de 20 bacias rurais, há o estudo anterior de Ven te Chow que apresenta uma equação de tempo de pico (DAEE, 1978), que pode ser adaptada para tempo de concentração via um fator.

A equação do tempo de concentração de Dooge, baseada em dados de dez bacias rurais da Irlanda, com áreas entre 140 e $930 \mathrm{~km}^{2}$, deve refletir melhor o tempo de concentração em bacias onde predomina o escoamento em canais (Porto, 1995).
Numa faixa mais estendida de bacias (65 a 4.200 $\mathrm{km}^{2}$ ) tem-se a disponibilidade da equação de Johnstone, que realizou seu estudo com dados de 19 bacias americanas (USDA, 1973). Baseada em uma faixa mais ampla ainda de bacias rurais (até cerca de $12.000 \mathrm{~km}^{2}$ ) existe a fórmula do Corps of Engineers do exército americano (MOPU, 1987). As equações de Johnstone e do Corps of Engineers deveriam refletir efeitos de armazenamento importantes porque estão baseadas em dados de bacias de grande porte. Poderiam, por isso, superestimar os tempos de concentração quando aplicadas a bacias menores.

A fórmula de Giandotti, junto com as de Ventura e Pasini, compõem o trio mais conhecido de fórmulas de tempo de concentração italianas. A fórmula de Giandotti é referida na bibliografia consultada de Correia (1983) e MOPU (1987). As fórmulas de Ventura e Pasini, por sua vez, são usadas eventualmente no Brasil, provavelmente por terem sido citadas por Pfafstetter (1976). Entretanto, nesta publicação não se encontra nenhuma referência bibliográfica direta, nem informações acerca de sua obtenção e aplicabilidade.

Buscas na internet com a palavra chave "tempo di corrivazione" (tempo de concentração em italiano) apontam diversas referências às fórmulas de Ventura, Pasini e Giandotti. No entanto, talvez pela antigüidade e familiaridade, mesmo nas publicações italianas que as empregam, não se encontram referências às suas respectivas bibliografias originais, consequentemente, suas condições de obtenção são obscuras aos pesquisadores de hoje. Por outro lado, exemplos de estudos hidrológicos italianos divulgados na internet, aliados ao fato da conformação geográfica da Itália limitar o tamanho das bacias hidrográficas, permitem especular que são fórmulas indicadas para pequenas a médias bacias rurais.

Com a mesma dificuldade de saber sua origem e aplicabilidade está a equação de Picking, cuja referência consultada (Pinto et al, 1976), nada diz sobre isso.

Com autoria brasileira, temos as equações de tempo de concentração de George Ribeiro, uma que leva seu próprio nome (Garcez, 1967), e outra que leva o nome do antigo Departamento Nacional de Obras de Saneamento, DNOS, que a adotou (Mello, 1973). As informações sobre origem e aplicabilidade dessas equações não estão disponíveis nessas referências indicadas. Entretanto, uma pesquisa no acervo da Revista do Clube de Engenharia do Rio de Janeiro, esclarece alguns aspectos. A equação do DNOS foi proposta originalmente como uma adaptação da fórmula de Bransby-Williams 
(EUA), de 1923, onde George Ribeiro introduziu um fator de rugosidade com um raciocínio empírico (Ribeiro, 1955). Foi verificada com os dados de Ramser, o que a colocaria no mesmo patamar de credibilidade da equação de Kirpich. Destaque-se, entretanto, que a fórmula de Bransby-Williams (EUA), de 1923, utilizada por George Ribeiro, é completamente diferente daquela publicada por Wanielista et al (1997) referida como de 1922.

A outra equação, efetivamente conhecida como a de George Ribeiro, foi proposta em 1961 (Ribeiro, 1961), buscando uma base física ao fazer a razão do comprimento do talvegue, afetado por um coeficiente, pela velocidade média de escoamento, dada por uma potência da declividade do talvegue multiplicada por um fator de rugosidade. $O$ fator de rugosidade foi considerado como uma função linear da porcentagem da bacia coberta com mata. George Ribeiro calibrou sua equação por mínimos quadrados com os dados das seis bacias de Ramser-Kirpich mais dados de outras bacias que não discrimina. Entretanto, pode-se inferir, pela sua publicação de 1955, que muito provavelmente utilizou dados de apenas mais duas bacias, uma da Índia com 18.650 $\mathrm{km}^{2}$ e outra dos EUA com $58 \mathrm{~km}^{2}$. A discrepância de magnitudes entre essas bacias e as de Ramser (0,5 a 45 hectares) não garantiriam, a princípio, uma maior representativiodade em relação à sua equação anterior (equação do DNOS), como afirmou Ribeiro (1961).

Para as equações de tempo de concentração urbanas há várias fontes internacionais. As informações de Schaake et al (1967), Desbordes (1974) e McCuen et al (1984) foram utilizadas no presente estudo, incluindo as próprias fórmulas de tempo de retardo ou de concentração desses autores. Do artigo de McCuen et al (1984) retiraram-se as informações sobre as equações de tempo de concentração de Carter, Eagleson e Espey-Winslow. A equação de tempo de concentração derivada do estudo de Schaake et al (1967) é baseada em dados de 19 bacias urbanizadas americanas muito pequenas, de áreas inferiores a 63 hectares. Para uma faixa superior, até 16 a $21 \mathrm{~km}^{2}$, foram desenvolvidas as equações de McCuen et al (1984), Carter e Eagleson. A de Carter destaca-se por representar bacias de baixa declividade do talvegue (menor que 0,5\%). Desbordes (1974) utilizou os dados de algumas das bacias de Schaake et al (1967) e de bacias francesas, numa amostra de 21 bacias até $51 \mathrm{~km}^{2}$. Já Espey-Winslow, citado por McCuen et al (1984), utilizou 17 bacias até $91 \mathrm{~km}^{2}$.

O estudo de McCuen et al (1984) aponta as fórmulas de Eagleson e Espey-Winslow como as de menor erro médio ( $-4 \%$ e $-6 \%$, respectivamente). Entretanto, o estudo foi muito criticado porque McCuen et al (1984) consideraram como tempos de concentração "observados" valores estimados por somatória de tempos de trânsito calculados com informações de trajetos e cobertura do solo. Ou seja, a referência "observada" de McCuen et al (1984) consiste de tempos de concentração muito provavelmente exagerados.

\section{Avaliação das fórmulas}

A metodologia escolhida para avaliação e comparação das fórmulas de tempo de concentração é simples e baseia-se nos erros médios percentuais (EM) de cada fórmula na sua faixa de áreas de melhor desempenho :

$$
E M=\frac{100}{n} \sum_{i=1}^{n} \frac{T_{C C}-T_{C O}}{T_{C O}}
$$

onde Tcc e Tco são, respectivamnete, os tempos de concentração calculados (pela fórmula em análise) e observados; n é o número de bacias considerado na análise.

A seleção das faixas de áreas de melhor desempenho de cada fórmula foi realizada identificando-se a seqüência de bacias ordenadas por área onde se concentrava o maior número de casos onde $\mathrm{EM}$, em valores absolutos, fosse menor ou igual a $30 \%$. Esta seqüência deveria ter o maior número possível de bacias (desde que maior que cinco) e ter mais da metade dos valores absolutos de EM menores ou iguais a $30 \%$.

Com este critério avalia-se o erro médio percentual EM e seu desvio-padrão, ou erro-padrão $\mathrm{EP}$, de cada fórmula de tempo de concentração selecionada.

$$
E P=\frac{1}{n-1} \sum_{i=1}^{n}\left(100 \frac{T_{C C}-T_{C O}}{T_{C O}}-E M\right)^{2}
$$

onde Tcc, Tco e n têm as mesmas definições anteriores da expressão de EM.

Estas estatísticas EM e EP, aliadas à gama de áreas de bacia identificada como mais adequada a cada fórmula (Tabela 7), permitem realizar observações sobre seus desempenhos e comparações. Cada fórmula foi avaliada com respeito a todos os tempos de concentração observados em bacias de arquivosteste que foram organizados em função de sua dis- 
ponibilidade na bibliografia consultada (dados oriundos de análises de hietogramas e hidrogramas).

Tabela 8 - Dados do Arquivo-Teste Rural

\begin{tabular}{llllll}
\hline N & Bacia & A km² & L & S & Tc \\
& & & $\mathrm{km}$ & $\mathrm{m} / \mathrm{m}$ & horas \\
\hline 1 & W1 Edwardsville, Illinois & 0,11 & 0,24 & 0,0180 & 0,14 \\
2 & W4 Edwardsville, Illinois & 1,173 & 1,48 & 0,0110 & 0,51 \\
3 & Barr. Oak, California & 6 & 4,7 & 0,1326 & 1,13 \\
4 & Barr. Eaton Wash, Calif & 25 & 12 & 0,1136 & 1,84 \\
5 & Barr. Santa Anita, Calif. & 28 & 9 & 0,1309 & 1,56 \\
6 & Rierra del Abanco, Esp. & 35 & 11,1 & 0,0655 & 1,98 \\
7 & Rio Sabar, Alfarnatejo & 39 & 8,8 & 0,0684 & 2,41 \\
8 & Barr. San Dimas, Calif. & 42 & 14 & 0,0833 & 2,13 \\
9 & Rio San Antonio, Calif. & 44 & 9,5 & 0,1926 & 1,70 \\
10 & Barr. Pacoima, California & 72 & 24 & 0,0597 & 3,40 \\
11 & Rio San Gabriel, EUA & 105 & 13 & 0,0852 & 2,27 \\
12 & Rio Guadalmedina, Esp. & 153 & 44,6 & 0,0304 & 4,25 \\
13 & Skunk Phoenix, Arizona & 167 & 28 & 0,0169 & 3,40 \\
14 & Rio Camba, Espanha & 168 & 34 & 0,0205 & 7,09 \\
15 & Rio New, R.Springs, Ariz & 174 & 33 & 0,0267 & 4,39 \\
16 & Barragem Tujunga, Calif. & 211 & 24 & 0,0549 & 3,54 \\
17 & Rio New, N. River, Ariz & 222 & 37 & 0,0275 & 5,24 \\
18 & Barr. Sepulveda, Calif. & 394 & 30,5 & 0,0275 & 4,96 \\
19 & Barr. San Gabriel, Calif. & 420 & 37 & 0,0663 & 4,68 \\
20 & Temecula Pauba, Calif. & 435 & 42 & 0,0284 & 5,24 \\
21 & Rio New Bell Road, Ariz & 484 & 77 & 0,0157 & 7,51 \\
22 & Temecula Murrieta, & 570 & 44 & 0,0180 & 5,67 \\
Calif. & & & & \\
23 & Rio Sta Clara, Calif. & 919 & 58 & 0,0265 & 7,94 \\
24 & R. S. Margarita, Fall- & 1670 & 74 & 0,0199 & 10,34 \\
brook & & & & \\
26 & Rio B. Margarita, Ysidora & 1917 & 98 & 0,0161 & 13,46 \\
27 & Rio San Francisco, Ariz. & 5180 & 209 & 0,0061 & 29,19 \\
28 & Rio Gila, Barr. 4, Ariz. & 7355 & 211 & 0,0055 & 30,47 \\
29 & Rio Salt, Roosevelt, Ariz. & 11162 & 257 & 0,0085 & 26,36 \\
\hline
\end{tabular}

Preparou-se um arquivo-teste com dados de bacias rurais e outro com dados de bacias urbanas. Optou-se por testar todas as equações com os dados destes dois arquivos, mesmo que as fórmulas não tenham aplicabilidade presumida de origem, por serem classificadas em urbanas ou rurais. É realmente discutível testar uma fórmula de tempo de concentração ajustada com dados de bacias urbanas com dados de bacias rurais e vice-versa. Entretanto, na prática da engenharia não raro encontram-se situações desse tipo, como, por exemplo, a aplicação da equação de Kirpich original a bacias urbanas. De qualquer forma, jogou-se com a possibilidade dos testes revelarem desempenhos surpreendentes, ao acaso ou por razões lógicas.

\section{Arquivo-teste rural}

Trata-se de um conjunto de dados compilados de bacias rurais americanas junto com algumas bacias espanholas incorporadas pela Direção Geral de Estradas da Espanha (MOPU, 1987).

MOPU (1987) apresenta as bacias da Tabela 8 com os tempos de retardo, mas eles foram multiplicados por 1,417 para obter o tempo de concentração. A gama de áreas das 29 bacias do ArquivoTeste MOPU é ampla, entre 0,1 a $12.000 \mathrm{~km}^{2}$, assim como seus tempos de concentração de 0,1 a 30 horas, aproximadamente. Os comprimentos $\mathrm{L}$ e as declividades médias $\mathrm{S}$ são apresentados como referentes ao curso d'água principal da bacia, sem especificar seu modo de obtenção. Uma fórmula com bom desempenho geral neste arquivo poderia ser considerada uma fórmula robusta.

Arquivo-teste urbano

O arquivo-teste urbano foi composto pelos dados contidos nos estudos de Schaake et al (1967) e Desbordes (1974). Schaake et al (1967) publicaram dados de 19 micro-bacias urbanas na faixa de 0,08 a 62 hectares. O próprio Desbordes (1974) agregou dados de oito dessas bacias ao seu estudo, mesclando-as aos dados de bacias francesas instrumentadas e outras americanas. A reunião dos dados desses estudos perfaz 32 bacias urbanas com dados (Tabela 9). O resultado, em termos de representatividade, foi o estabelecimento de um arquivo ou banco de dados de bacias urbanas com um espectro de áreas e impermeabilizações variadas, mas com predominância de bacias com menos de $1 \mathrm{~km}^{2}$. Os tempos de retardo foram multiplicados por 1,417 para expressar tempos de concentração, conforme indica McCuen et al (1984). Os comprimentos L e as declividades médias $\mathrm{S}$ são referentes ao talvegue ou coletror principal da bacia, sem especificar seu modo de obtenção.

Até 5 hectares de área há 18 bacias. Com estas micro-bacias, o perfil buscado na avaliação das fórmulas de tempo de concentração é justamente verificar se há possibilidade de diferentes fórmulas desempenharem bem também frente a bacias muito pequenas. Em outras palavras se é possível uma fórmula de tempo de concentração calcular bem tanto em micro-bacias como em bacias maiores. Acima de 5 hectares até $50 \mathrm{~km}^{2}$, há dados de 14 bacias, sendo representativas de um espectro abrangente, das micro-bacias a bacias de córregos urbanos de maior porte. 


\section{Tabelas dos arquivos-teste rural e urbano}

Estão nas Tabelas 8 e 9 a seguir. Nelas podem ser vistas as informações de área contribuinte, comprimento do talvegue principal, declividade média deste e o tempo de concentração. No arquivo das bacias urbanas há a informação também da taxa de área impermeável.

Tabela 9 - Dados do Arquivo-Teste Urbano

\begin{tabular}{|c|c|c|c|c|c|c|}
\hline $\mathrm{N}$ & Bacia $(*)$ & $\begin{array}{l}\text { Área } \\
\mathrm{km}^{2}\end{array}$ & $\begin{array}{l}\mathrm{A}_{\text {imp }} \\
\%\end{array}$ & $\begin{array}{l}\mathrm{L} \\
\mathrm{km}\end{array}$ & $\begin{array}{l}\mathrm{S} \\
\mathrm{m} / \mathrm{m}\end{array}$ & $\begin{array}{l}\text { Tc } \\
\text { horas }\end{array}$ \\
\hline 1 & Hamil & 0,00087 & 96,3 & 0,178 & 0,0086 & 0,12 \\
\hline 2 & Sth Park. Lot 1 & 0,00160 & 100 & 0,085 & 0,0171 & 0,11 \\
\hline 3 & Montebello 3 & 0,00183 & 57,1 & 0,047 & 0,0081 & 0,09 \\
\hline 4 & Sth Park. Lot 2 & 0,00190 & 100 & 0,101 & 0,0216 & 0,16 \\
\hline 5 & Montebello 5 & 0,00212 & 65,9 & 0,107 & 0,0085 & 0,09 \\
\hline 6 & Montebello 4 & 0,00219 & 64,8 & 0,107 & 0,0079 & 0,08 \\
\hline 7 & Newark 9 & 0,00257 & 100 & 0,175 & 0,0335 & 0,08 \\
\hline 8 & Hamilton 2 & 0,00378 & 20,1 & 0,154 & 0,0098 & 0,21 \\
\hline 9 & Newark 10 & 0,00386 & 100 & 0,280 & 0,0068 & 0,12 \\
\hline 10 & Midwood 5 & 0,00516 & 56 & 0,110 & 0,0610 & 0,07 \\
\hline 11 & Montebello 2 & 0,00612 & 8,7 & 0,143 & 0,0173 & 0,19 \\
\hline 12 & Hamilton 5 & 0,00692 & 31,8 & 0,110 & 0,0210 & 0,11 \\
\hline 13 & Hamilton 3 & 0,00742 & 36,4 & 0,178 & 0,0085 & 0,17 \\
\hline 14 & Sogreah 1 & 0,015 & 70 & 0,286 & 0,008 & 0,24 \\
\hline 15 & Sogreah 3 & 0,030 & 52 & 0,660 & 0,047 & 0,32 \\
\hline 16 & Sogreah 6 & 0,036 & 100 & 0,450 & 0,004 & 0,33 \\
\hline 17 & Yorkwood & 0,042 & 41 & 0,317 & 0,0351 & 0,11 \\
\hline 18 & Sogreah 2 & 0,046 & 78 & 0,518 & 0,005 & 0,39 \\
\hline 19 & Sogreah 5 & 0,053 & 22 & 0,433 & 0,019 & 0,35 \\
\hline 20 & Sogreah 4 & 0,055 & 39 & 0,990 & 0,041 & 0,27 \\
\hline 21 & Gray Haven & 0,094 & 52 & 0,569 & 0,0091 & 0,20 \\
\hline 22 & Sarma 1 & 0,119 & 38 & 1,064 & 0,021 & 0,28 \\
\hline 23 & Uplands & 0,122 & 52 & 0,635 & 0,0256 & 0,17 \\
\hline 24 & Swansea & 0,191 & 44 & 0,610 & 0,0306 & 0,11 \\
\hline 25 & Northwood & 0,192 & 68 & 0,690 & 0,0287 & 0,15 \\
\hline 26 & Walker Avenue & 0,621 & 33 & 1,713 & 0,0142 & 0,27 \\
\hline 27 & Sarma 2 & 1,59 & 37,4 & 3,054 & 0,021 & 0,87 \\
\hline 28 & Sarma 6 & 5,98 & 27 & 7,033 & 0,0089 & 2,39 \\
\hline 29 & Sarma 7 & 10,7 & 37 & 8,417 & 0,0089 & 1,52 \\
\hline 30 & Sarma 3 & 19,6 & 10,5 & 6,151 & 0,0024 & 5,63 \\
\hline 31 & Sarma 4 & 26,2 & 15,5 & 9,083 & 0,0027 & 5,03 \\
\hline 32 & Sarma 5 & 50,1 & 2,1 & 17,864 & 0,0044 & 18,54 \\
\hline
\end{tabular}

(*) identificação numerada dada por Desbordes (1974)

\section{RESULTADOS}

Os resultados obtidos com base no estabelecido na metodologia estão sintetizados nas Tabela 10. Para maior clareza, os valores dos erros médios porcentuais foram arredondados para o inteiro.

Bacias Rurais

Há resultados surpreendentes. Por exemplo, há fórmulas obtidas com dados de parcelas que inesperadamente funcionaram bem para bacias de porte, caso das fórmulas da Onda Cinemática e Izzard, com erros médios de $2 \%$ e $6 \%$, respectivamente. Inclusive com erros-padrão também pequenos (20\% e $24 \%$, respectivamente).

Esses desempenhos chegam a superar até os desempenhos de fórmulas rurais para bacias de porte (Tabela 7), que são as fórmulas de Dooge, Johnstone e Corps of Engineers. De fato, o melhor desempenho destas três, e único que satisfaz (com critério de erro absoluto menor que $10 \%$ ), é o do Corps of Engineers cuja fórmula foi ajustada originalmente com praticamente todos os dados do arquivo-teste rural. A fórmula de tempo de concentração do Corps of Engineers teve erro médio de $9 \%$ e erro padrão de $21 \%$, avaliado para toda a gama de bacias analisadas (de 0,11 a $11.162 \mathrm{~km}^{2}$ ). As fórmulas de Dooge e Johnstone tiveram erros de 29 e $26 \%$, respectivamente

Outros resultados inesperados para bacias rurais de grande porte foram os obtidos com as fórmulas de Kirpich e Ven te Chow. A primeira, cuja validade teórica seria para bacias até $0,45 \mathrm{~km}^{2}$ funcionou bem para bacias entre 153 e $11.162 \mathrm{~km}^{2}$, com erro de $-9 \%$ e erro padrão de $19 \%$. A de Ven te Chow, também com validade teórica restrita (bacias até $19 \mathrm{~km}^{2}$ ), funcionou igualmente bem de 6 a $11.162 \mathrm{~km}^{2}$, apresentando erro médio de $-7 \%$, com igual erro-padrão da de Kirpich. A Figura 1, ao fim do artigo, ilustra alguns resultados

Os resultados da fórmula do DNOS, de acordo com o uso recomendado na prática, não pode ser a rigor taxado de surpreendente. Ela atingiu um erro médio de $8 \%$, com erro padrão de $30 \%$, e abrangeu uma gama de áreas de 25 a $420 \mathrm{~km}^{2}$. Esta faixa de áreas costuma-se observar nas aplicações da fórmula do DNOS, mas, conforme se mostrou anteriormente, os dados de origem são os mesmos de Kirpich, portanto, seria válida apenas para áreas até $0,45 \mathrm{~km}^{2}$.

As demais fórmulas rurais não tiveram desempenhos bons com as bacias rurais, mas isto era esperado em função da magnitude da maioria das bacias do arquivo-teste rural. Assim as fórmulas do SCS lag e Picking não conseguiram nenhum resultado significativo e as fórmulas restantes (SimasHawkins, as italianas Giandotti, Pasini e Ventura e a "brasileira" George Ribeiro) superestimaram o tempo de concentração entre 18 e $25 \%$. As fórmulas de 
Tabela 10 - Erros das fórmulas de Tc

\begin{tabular}{ccccccccc}
\hline Nome & BR & Áreas $\left(\mathrm{km}^{2}\right)$ & $\begin{array}{c}\text { EM } \\
\%\end{array}$ & $\begin{array}{c}\text { EP } \\
\%\end{array}$ & BU & Áreas (ha) & $\begin{array}{c}\text { EM } \\
\%\end{array}$ & $\begin{array}{c}\text { EP } \\
\%\end{array}$ \\
\hline Izzard & 23 & $25-2046$ & 6 & 24 & 10 & $0,6-6$ & 32 & 37 \\
Kerby-H. & 16 & $168-11162$ & 18 & 26 & 26 & $0,1-62$ & -7 & 32 \\
Onda Cin. & 27 & $6-11162$ & 2 & 20 & 18 & $0,2-5$ & 34 & 52 \\
FAA & 16 & $168-11162$ & 37 & 28 & 22 & $0,2-12$ & -6 & 34 \\
Kirpich & 18 & $153-11162$ & -9 & 19 & 16 & $4-2620$ & 1 & 39 \\
SCS Lag & - & - & - & - & 6 & $0,5-3$ & 15 & 34 \\
Simas-H. & 9 & $484-11162$ & 21 & 43 & 5 & $160-2620$ & 1 & 32 \\
V. Chow & 27 & $6-11162$ & -7 & 19 & 11 & $0,2-0,7$ & 52 & 71 \\
Dooge & 26 & $6-7355$ & 29 & 24 & 12 & $0,2-4$ & -32 & 17 \\
Johnstone & 23 & $39-11162$ & 26 & 29 & - & - & - & - \\
Corps E. & 29 & $0-11162$ & 9 & 21 & 16 & $0,2-6$ & -8 & 32 \\
Giandotti & 25 & $6-11162$ & 25 & 28 & - & - & - & - \\
Pasini & 7 & $6-44$ & 20 & 25 & 16 & $0,2-6$ & -22 & 30 \\
Ventura & 8 & $6-72$ & 18 & 22 & 14 & $0,2-5$ & -29 & 29 \\
Picking & - & - & - & - & 25 & $0,2-1070$ & 3 & 40 \\
DNOS & 16 & $25-420$ & 8 & 30 & 16 & $4-2620$ & -10 & 39 \\
G. Ribeiro & 6 & $1-39$ & 23 & 34 & 9 & $6-600$ & 4 & 26 \\
Schaake & - & - & - & - & 26 & $0,1-62$ & -9 & 30 \\
McCuen & - & - & - & - & 11 & $0,5-6$ & 5 & 28 \\
Carter & - & - & - & - & 29 & $0,2-1070$ & 1 & 40 \\
Eagleson & 15 & $72-1670$ & 9 & 39 & 7 & $2-6$ & -9 & 29 \\
Desbordes & - & - & - & - & 20 & $0,2-5100$ & 11 & 49 \\
Espey & - & - & - & - & 7 & $5-19$ & 32 & 38 \\
\hline
\end{tabular}

(-) sem resultado no critério adotado

$\mathrm{BR}$ : número de bacias rurais

$\mathrm{BU}$ : número de bacias urbanas

Simas-Hawkins e Giandotti surpreendem, entretanto, pela ampla faixa de áreas com potencial aceitabilidade de uso. Por outro lado, as faixas de áreas de validade prática das fórmulas de Pasini, Ventura e George Ribeiro parecem estar coerentes com sua aplicação prática a pequenas bacias rurais.

Quanto a um resultado significativo de fórmulas urbanas com uso forçado em bacias rurais, o único obtido foi com a fórmula de Eagleson, confirmando a expectativa de, no geral, as fórmulas urbanas não funcionarem bem em bacias rurais. A fórmula de Eagleson obteve erro médio de $9 \%$ para uma gama de bacias de 72 a $1.670 \mathrm{~km}^{2}$.

\section{Bacias Urbanas}

Em termos de erro médio absoluto a fórmula de Carter desponta com apenas 1\%, mas seu erro padrão de $40 \%$ parece elevado (considerado bom somente quando menor ou igual a $30 \%$ ). Há coerência da fórmula de Carter no que tange à gama de áreas de aplicação (a Tabela 10 aponta áreas até 11 $\mathrm{km}^{2}$, enquanto que a Tabela 7 dá validade até 21 $\mathrm{km}^{2}$ ). A Figura 2, ao fim do artigo, ilustra este resultado e alguns outros.

A fórmula de McCuen foi a fórmula urbana que apresentou o menor erro-padrão (28\%), apresentando ainda um erro médio de apenas $5 \%$. Entretanto, esse desempenho está restrito a bacias de até 6,0 hectares, muito aquém de sua recomendação teórica (até $16 \mathrm{~km}^{2}$ ). Por outro lado, a fórmula de Schaake confirmou sua gama de áreas teórica (inferior a 70 hectares), com bom desempenho (erro médio de $-9 \%$ e erro-padrão de $30 \%$ ). Desempenho semelhante teve a fórmula de Eagleson, só que para bacias menores que 6,0 hectares.

A fórmula de Desbordes, pelos critérios adotados, não teve um desempenho bom (erro médio de $11 \%$ e erro-padrão de $49 \%$ ), apesar de manter coerência com respeito à gama de áreas de aplicação (até $51 \mathrm{~km}^{2}$ ). Já a fórmula de Espey-Winslow desempenhou-se mal por todos os critérios. 

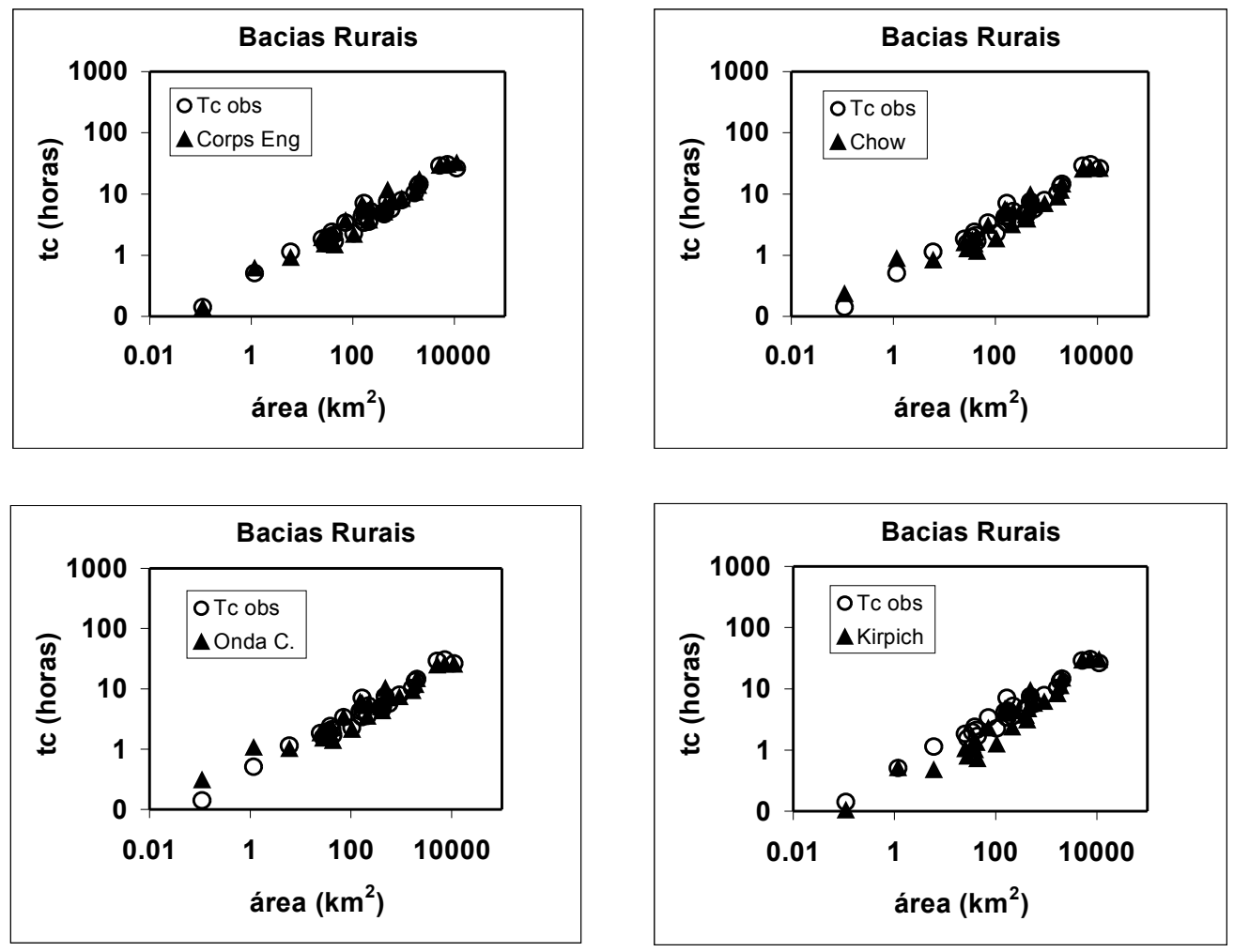

Figura 1 - Exemplos de tempos de concentração calculados em bacias rurais

Merecem algum destaque na aplicação a bacias urbanas, as fórmulas de "parcela", na prática muito usadas mesmo em bacias urbanas. As fórmulas da FAA e Kerby-Hathaway tiveram erros médios reduzidos (-6 e $-7 \%$, respectivamente), mas seus erros padrão estiveram um pouco elevados (34 e $32 \%$, respectivamente). A fórmula de KerbyHathaway teve resultados equivalentes à fórmula de Schaake, inclusive na gama de áreas (Tabela 10). De modo geral, as fórmulas de parcela, mesmo as que não deram bons resultados (Izzard e Onda Cinemática) guardaram coerência no que tange à magnitude das bacias urbanas.

No que tange ao desempenho de fórmulas "rurais" em bacias urbanas há casos que merecem destaque. Um deles refere-se à fórmula de Picking, que, na verdade, foi enquadrada como "rural" arbitrariamente. Em termos de erro médio absoluto a fórmula de Picking ressalta com apenas 3\%, mas seu erro padrão de é de $40 \%$. De qualquer forma, como não foi possível identificar a origem da fórmula de Picking, é grande a possibilidade dela ser uma ver- dadeira fórmula de tempo de concentração urbana. Com o melhor desempenho, em termos de erro padrão, em bacias urbanas por parte de uma fórmula "rural" vem a equação de George Ribeiro. De 6 a 600 hectares, a fórmula de George Ribeiro obteve um erro de $4 \%$ e erro-padrão de $26 \%$. Nesta faixa de áreas chega a superar, portanto, a fórmula urbana de Carter.

Merecem algum destaque as fórmulas rurais de Kirpich, Simas-Hawkins e Corps of Engineers e seu desempenho em bacias urbanas. A fórmula de Kirpich possui desempenho similar à de Carter com a vantagem de avançar a gama de áreas até $26 \mathrm{~km}^{2}$. A fórmula de Simas-Hawkins tem desempenho até um pouco melhor que a de Kirpich mas sua representatividade é bem menor (somente cinco bacias obedeceram o critério de avaliação). A fórmula do Corps of Engineers surpreende ao selecionar bacias urbanas abaixo dos seis hectares, com erros similares à fórmula de Eagleson. As demais fórmulas rurais não apresentaram resultados significativos nas bacias urbanas, como esperado. 

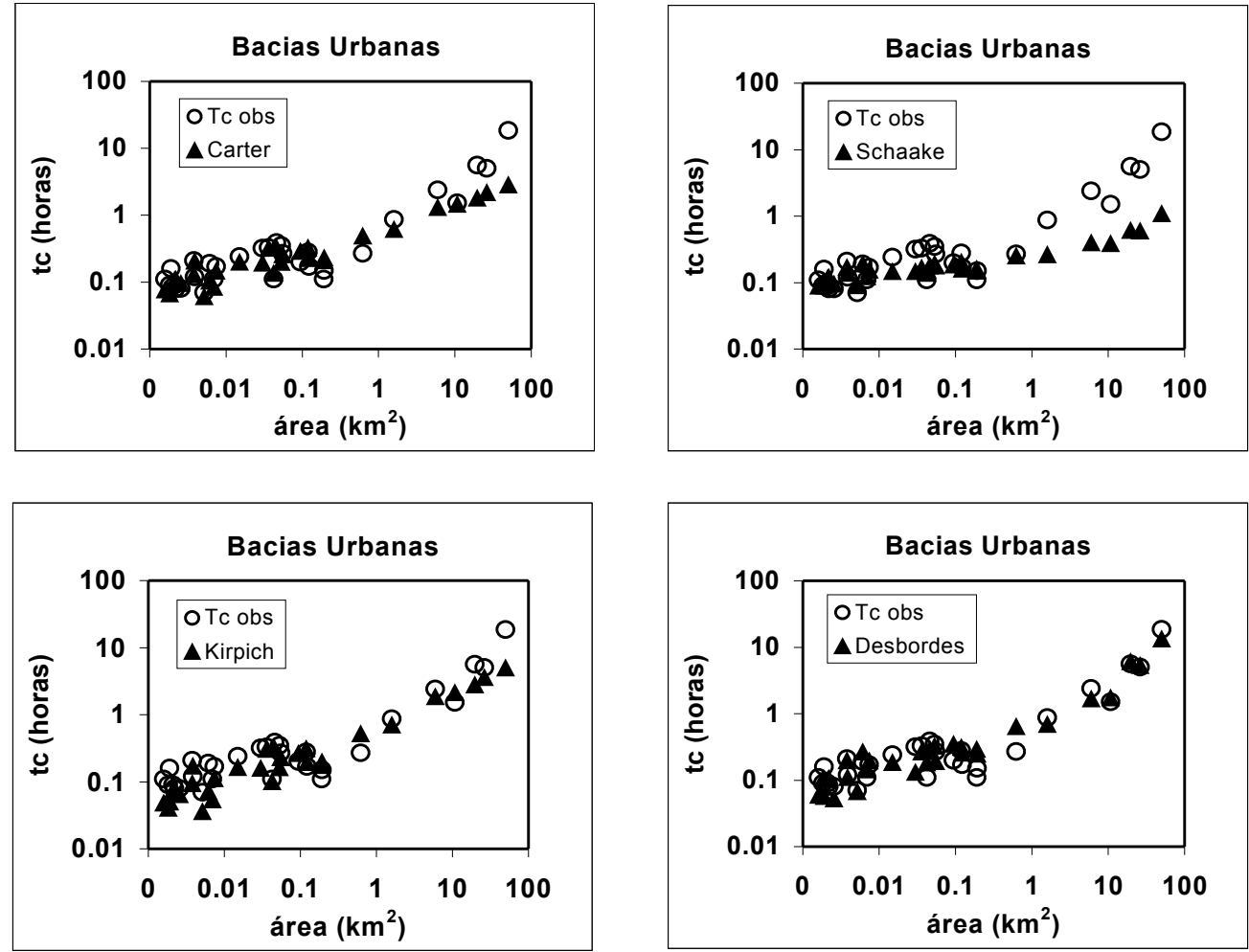

Figura 2 - Exemplos de tempos de concentração calculados em bacias urbanas

\section{DISCUSSÃO}

Colocando-se em perspectiva os resultados obtidos pode-se realizar alguma discussão por tipo de fórmula e tipo de bacia.

\section{Fórmulas de Parcela}

As fórmulas de Izzard e Onda Cinemática deram bons resultados (erros médios absolutos $<10 \%$ ) na estimativa de tempos de concentração de bacias rurais de médio e grande porte, contrariando expectativas. Por outro lado, as fórmulas de KerbyHathaway e FAA tiveram seus melhores resultados onde era esperado, ou seja, em bacias urbanas muito pequenas.

As fórmulas de Izzard e Onda Cinemática têm a intensidade de chuva como variável explicativa, característica ausente nas fórmulas de KerbyHathaway e FAA. A questão que se coloca é se isto pode explicar os desempenhos contrastantes da primeira dupla de fórmulas em comparação com a segunda. Com as informações disponíveis não é possível evidenciar isto. O que se pode afirmar é que as diferenças de desempenhos encontradas podem ser minimizadas com escolhas ou ajustes convenientes dos parâmetros de rugosidade e mesmo da intensidade referencial de chuva. Em outras palavras, os resultados dependem muito do que foi estabelecido a priori na Tabela 5. De qualquer forma, podese concluir que o fato de uma fórmula ter sido estabelecida com dados de parcela não impede que elas tenham bom desempenho em pequenas bacias urbanas e bacias rurais até mesmo de grande porte.

\section{Fórmulas Rurais}

Com respeito à sua aplicação de ofício, ou seja, aplicação a bacias rurais, as fórmulas rurais tiveram desempenhos variados. O grupo formado pelas fórmulas de Kirpich, Ven te Chow, Corps of Engineers e DNOS obteve bons resultados. As três primeiras usam apenas $\mathrm{L}$ e $\mathrm{S}$ como variáveis explicativas (embutindo nos coeficientes os demais fatores do tempo de concentração) e isto poderia indicar algo. Poderia se especular que, aparentemente, a maior homogeneidade dos fatores de escoamento das bacias rurais (rugosidade entre eles) sugere coeficientes mais estáveis, mesmo que a gama de 
áreas de bacia seja grande. Assim a estabilidade desses coeficientes repassaria a totalidade da explicação da variabilidade do tempo de concentração para os fatores físicos L e S. Entretanto, se o coeficiente não é representativo, como parece ser o caso das fórmulas de Johnstone e Picking, os resultados não são bons.

Por outro lado, a maioria das fórmulas que utiliza a área A da bacia como uma variável explicativa (Simas-Hawkins, Dooge, Giandotti, Pasini e Ventura) exibe a tendência de superestimação do tempo de concentração, independente da amplitude das áreas aceitas para as fórmulas. Não há evidência científica maior, mas parece que a variável A não contém a mesma informação que $\mathrm{L}$ aporta para o tempo de concentração. Mesmo que L esteja presente junto com A, ela viria a degradar a informação desta. Sabe-se que A e L têm alguma correlação, mas enquanto A informa basicamente a magnitude, $\mathrm{L}$ traduz uma informação física diretamente ligada a tempos de escoamento.

Com respeito a aspectos práticos deve-se notar que apenas a fórmula do Corps of Engineers tinha respaldo experimental para grandes bacias (até cerca de $12.000 \mathrm{~km}^{2}$ ) porque usou praticamente as mesmas bacias do arquivo-teste rural desse artigo. Talvez, por isso, tenha sido a fórmula com maior representatividade rural (29 bacias selecionadas na Tabela 10) e seu bom resultado não seja surpreendente (mas o fato é que ela se ajusta bem os dados).

No caso da fórmula de Kirpich há uma espécie de confirmação do que se verifica muito na prática de hidrologia no Brasil, isto é, que ela pode ser usada com bons resultados em bacias rurais de médio e grande porte, a despeito de sua calibração com dados de bacias pequeníssimas do Tennessee (EUA). Além de apresentar um erro médio bastante razoável para bacias entre 150 e $12.000 \mathrm{~km}^{2}$, cerca de $-9 \%$, revelou ter também um erro padrão reduzido, $19 \%$, o menor de todas as fórmulas, juntamente com a de Ven te Chow. Aliás, esta apresenta o melhor resultado dentre as fórmulas rurais (erro médio de $-7 \%$ ), revelando também uma extraordinária potencialidade de extrapolação, até cerca de 12.000 $\mathrm{km}^{2}$.

Curiosamente, tem-se, então a seguinte situação : das três melhores fórmulas de tempo de concentração para bacias rurais até cerca de $12.000 \mathrm{~km}^{2}$, apenas uma foi ajustada com dados de bacias até esta magnitude (Corps of Engineers). As outras duas (Kirpich e Ven te Chow), em relação a essa só apresentam diferença significativa no sinal do erro, pois ambas subestimam aproximadamente o que a do
Corps of Engineers superestima. Isto sugere inclusive que uma combinação de fórmulas poderia ajustar melhor os resultados, já que o erro padrão das três é semelhante. A fórmula do DNOS, freqüentemente utilizada no Brasil, apresentou erro similar à do Corps of Engineers, mas deve-se considerar que teve resultados consistentes apenas para a faixa de áreas de bacias rurais entre 25 e $400 \mathrm{~km}^{2}$, além de mostrar um erro padrão mais elevado. De qualquer forma ela é qualificada para uso no dimensionamento de uma série de obras hidráulicas de menor porte, como aliás faz o DAER/RS na drenagem de estradas. Sobre as fórmulas do SCS lag e Simas-Hawkins cabe comentários que amenizam seus resultados que não foram bons em bacias rurais. Elas usam o conhecido fator CN como variável explicativa do tempo de concentração e como houve a necessidade de lhes fixar valores iguais, já que não estavam disponíveis nos arquivos-teste das bacias, isto provavelmente prejudicou a obtenção de bons resultados. Algo semelhante pode ser dito sobre a fórmula de George Ribeiro, cujo mau resultado em bacias rurais pode ser somente conseqüência de ter-se fixado arbitrariamente o parâmetro "p" para todas as bacias-teste rurais. Já a fórmula de Picking não se mostrou adequada para nenhuma faixa de bacias rurais, sem motivo aparente.

As fórmulas rurais com erro médio absoluto menor ou igual a $10 \%$ em bacias urbanas foram as de Kirpich, Simas-Hawkins, Corps of Engineers, Picking, DNOS e George Ribeiro. Como a maioria dessas fórmulas possui variáveis explicativas convencionais (como A, L e S) parece evidente que a urbanização consegue ficar embutda nesses fatores físicos do tempo de concentração.

Das fórmulas citadas, a de Simas-Hawkins é a menos significativa, pois seu universo de melhor desempenho envolveu apenas cinco bacias urbanas. A fórmula de Picking aplicada em bacias urbanas atingiu um universo de 25 bacias até $11 \mathrm{~km}^{2}$ (Tabela 10) e apresentou erro médio de $3 \%$, reforçando a suspeita de que se trata de uma fórmula efetivamente urbana. Apenas apresenta um erro-padrão elevado de $40 \%$. A fórmula de Kirpich, em um universo de 16 bacias urbanas até $26 \mathrm{~km}^{2}$, apresentou desempenho semelhante, com erro médio de $1 \%$ e erropadrão de $39 \%$. A do DNOS vai até este limite de área e erro-padrão igual, mas seu erro médio atinge $10 \%$. As fórmulas de Corps of Engineers e George Ribeiro possuem erro padrão melhor, mas a primeira é aceitável para bacias urbanas de apenas seis hectares ou menos, limitando sua aplicação em bacias urbanas, tendo em vista a disponibilidade de outras fórmulas mais adequadas. A fórmula de Ge- 
orge Ribeiro, por sua vez, curiosamente teve seus melhores resultados em bacias urbanas do que nas rurais. Ela possui a vantagem, em relação às fórmulas genuinamente urbanas, de oferecer um erro médio de apenas $4 \%$ (com erro padrão de 26\%) para bacias até $6 \mathrm{~km}^{2}$. Mas deve-se considerar que seu universo foi de apenas nove bacias.

$\mathrm{O}$ que foi exposto neste item permite concluir que, a exemplo do que foi observado com as fórmulas de parcela, as fórmulas rurais não foram limitadas obrigatoriamente pelas características das bacias cujos dados lhes ajustaram. Inclusive, algumas fórmulas rurais apresentaram desempenho satisfatório em bacias urbanas.

\section{Fórmulas Urbanas}

A maioria das equações urbanas confirmou sua vocação para uso efetivo em bacias urbanas, mas somente três mostraram-se coerentes com as magnitudes de áreas de bacia teoricamente recomendáveis para elas: as fórmulas de Schaake, Carter e Desbordes. A outras que tiveram bons resultados ficaram aquém da expectativa, atingindo faixas de áreas muito restritas. A fórmula com maior representatividade urbana é a de Carter (29 bacias na Tabela 10, áreas até $11 \mathrm{~km}^{2}$ ), coincidentemente uma fórmula que utiliza apenas as variáveis explicativas $\mathrm{L}$ e S. Entretanto, apresenta erro-padrão (40\%) que é cerca do dobro daqueles das melhores fórmulas de aplicação rural.

Para bacias urbanas com áreas abaixo de 70 hectares a melhor fórmula é a de Schaake, mas é preciso reconhecer que ela foi ajustada a partir dos dados da maioria das bacias do arquivo-teste urbano nesta faixa de áreas. Acima de $11 \mathrm{~km}^{2}$, até $51 \mathrm{~km}^{2}$, apenas a fórmula de Desbordes dá resultados dentro do critério da metodologia, mas seu erro médio chega a $11 \%$ e seu erro-padrão é elevado ao nível de $49 \%$. Mas o que elevou muito esses índices foram as bacias 24, 25 e 26 da tabela 10, cuja retirada remete seu erro médio ao nível de $-1 \%$ e seu erro-padrão a $33 \%$ (a propósito a fórmula de Carter sem estas mesmas três bacias, abaixa seu erro-padrão também para $33 \%$, mas aumenta o erro médio para $-7 \%$, ainda bom). Com esse expurgo, fica mais claro que as fórmulas de Schaake, Carter e Desbordes, nas gamas de áreas onde desempenham melhor, satisfazem para bacias urbanas. A fórmula de KerbyHathaway pode concorrer com a de Schaake e a de George Ribeiro com a de Carter, mas nenhuma outra, seja de parcela ou rural, tem representatividade suficiente para uso alternativo prioritário em bacias urbanas.
Ao contrário do observado nas fórmulas rurais, nenhuma fórmula urbana teve capacidade de extrapolação de áreas de bacias e várias delas, inclusive, só desempenharam bem em faixas de áreas muito mais restritas que aquelas cujos dados lhes deram origem. A fórmula de Eagleson não pode ser caracterizada como exclusivamente urbana, assim, não foi surpresa ser a única fórmula "urbana" a ter algum resultado com bacias rurais.

Com respeito às fórmulas em comum, os resultados obtidos diferem significativamente daqueles de McCuen et al (1984). A provável explicação é que estes autores consideraram como tempos de concentração "observados" valores estimados por somatória de tempos de trânsito, portanto há grande probabilidade de desvio em relação aos valores reais.

\section{RECOMENDAÇÕES DE USO}

Com base nas avaliações realizadas este autor recomenda as fórmulas de tempo de concentração da Tabela 11, em que pese poder haver outras com potencial de uso, desde que se aceitem suas limitações como toleráveis ou se realizem novas avaliações que as indiquem consistentemente. $O$ leitor poderá fazer o próprio juízo com base nas informações da Tabela 10.

A ordem de preferência é indicada pelo número que antecede a letra $\mathrm{R}$ (bacias rurais) ou $\mathrm{U}$ (bacias urbanas).

Tabela 11 - Fórmulas de Tc recomendadas

\begin{tabular}{llllllll}
\hline & & \multicolumn{3}{l}{ Bacias rurais } & \multicolumn{4}{c}{ Bacias urbanas } \\
\cline { 3 - 8 } Fórmulas & Ordem & $\begin{array}{l}\text { Áreas } \\
\left(\mathrm{km}^{2}\right)\end{array}$ & EM\% & $\begin{array}{l}\text { EP } \\
\%\end{array}$ & $\begin{array}{l}\text { Áreas } \\
(\mathrm{ha})\end{array}$ & $\begin{array}{l}\text { EM } \\
\%\end{array}$ & $\begin{array}{l}\text { EP } \\
\%\end{array}$ \\
\hline Corps E. & $1 \mathrm{R}$ & $<12000$ & 9 & 21 & & & \\
V. Chow & $2 \mathrm{R}$ & $<12000$ & -7 & 19 & & & \\
Onda Cin. & 3R & $<12000$ & 2 & 20 & & & \\
Kirpich & $4 \mathrm{R}, 3 \mathrm{U}$ & $<12000$ & -9 & 19 & $<2700$ & 1 & 39 \\
Carter & 1U & & & & $<1100$ & 1 & 40 \\
Schaake & 2U & & & & $<62$ & -9 & 30 \\
Desbordes & $4 \mathrm{U}$ & & & & $<5100$ & 11 & 49 \\
\hline
\end{tabular}

As recomendações da Tabela 11 justificamse pela abrangência de bacias com bons resultados, pela representatividade original, e pelos erros avaliados. Assim, a fórmula do Corps of Engineers é a primeira recomendada para bacias rurais, vindo logo após a de Ven te Chow. Em terceiro, recomenda-se a da Onda Cinemática, que apesar de sua aplicabilidade natural a parcelas reduzidas, obteve resultados surpreendentemente muito bons para grandes 
bacias rurais. Em quarto e último, recomenda-se para bacias rurais, a fórmula de Kirpich, cujos resultados também não deixaram de ser surpreendentes, em função de sua proposição com dados somente de bacias muito pequenas.

As recomendações de uso para bacias urbanas seguiram os mesmos critérios. A que teve resultados satisfatórios em um maior número de bacias urbanas foi a fórmula de Carter. Em segundo lugar recomenda-se a de Schaake, mas para bacias com áreas muito reduzidas. Em terceiro lugar, pelo motivo de poder ser aplicada para bacias maiores que aquelas indicadas pela fórmula de Carter, indica-se a fórmula de Kirpich. Por último, recomenda-se a fórmula de Desbordes, mais em função de sua aplicabilidade a bacias com área da ordem de $50 \mathrm{~km}^{2}$, do que pelo seu desempenho (erro médio de $11 \%$ ).

\section{CONCLUSÃO}

Este artigo avaliou o desempenho de 23 fórmulas de tempo de concentração, com base em arquivos-teste de valores de tempo de concentração estimados a partir de tempos de retardo (lag times) disponíveis na literatura técnico-científica. Dois arquivos-teste foram considerados, um com 29 bacias rurais e outro com 32 bacias urbanas. As fórmulas de tempo de concentração foram previamente classificadas em "de parcela", "rurais" e "urbanas", conforme origem, mas a despeito disso foram testadas com todos os dados. Evidentemente, as conclusões que seguem decorrem da informação contida nestes arquivos-teste, assim deve-se considerar a incerteza neles embutidas em eventuais aplicações práticas das fórmulas testadas.

As fórmulas de "de parcela" de Izzard e Onda Cinemática conseguiram, surpreendentemente, boas estimativas de tempos de concentração para bacias rurais de médio e grande porte, além das pequenas. $\mathrm{O}$ caso mais extraordinário foi o da Onda Cinemática cuja fórmula de tempo de concentração poderia ser classificada como a melhor de todas para as bacias rurais, superando, inclusive, as melhores fórmulas consideradas "rurais". Por outro lado, as fórmulas de parcela de Kerby-Hathaway e FAA somente tiveram bons resultados em bacias urbanas muito pequenas, o que não surpreende. Não se encontrou uma razão física mais evidente para explicar esses desempenhos contrastantes, mas se pode afirmar que isto tem a haver com escolhas ou ajustes convenientes dos parâmetros de rugosidade e mesmo da intensidade referencial de chuva. De qualquer forma, pôde-se concluir que o fato de uma fórmula ter sido estabelecida com dados de parcela não impede que elas tenham bom desempenho desde pequenas bacias a grandes bacias rurais.

As fórmulas "rurais", grupo que incluiu as fórmulas de Kirpich, SCS lag, Simas-Hawkins, Ven te Chow, Dooge, Johnstone, Corps of Engineers, Giandotti, Pasini, Ventura, Picking, DNOS e George Ribeiro, mostraram desempenhos variados na sua aplicação de ofício, ou seja, aplicação a bacias rurais. O grupo formado pelas fórmulas de Kirpich, Ven te Chow e Corps of Engineers obteve melhores resultados. A fórmula do Corps of Engineers foi a única que foi ajustada com dados de bacias até $12.000 \mathrm{~km}^{2}$, sendo a mais consistente para ser recomendada. Mas as duas outras surpreenderam pelas faixas, também amplas, de áreas de bacia com bons resultados (150 a $12.000 \mathrm{~km}^{2}$ para Kirpich, e de 6 a de $12.000 \mathrm{~km}^{2}$, para Ven te Chow), já que ambas foram estabelecidas com dados experimentais de pequenas bacias, mais pronunciadamente a de Kirpich. No caso desta fórmula há uma espécie de confirmação do que se verifica muito na prática de hidrologia no Brasil, isto é, que ela pode ser usada com bons resultados em bacias rurais de médio e grande porte. As fórmulas de Kirpich, Ven te Chow e Corps of Engineers usam apenas L e S como variáveis explicativas, sugerindo grande estabilidade de fatores como a rugosidade, repassando a totalidade da explicação para estas variáveis físicas. Entretanto, se o coeficiente não é representativo, como parece ser o caso das fórmulas de Johnstone e Picking, os resultados não são bons. A maioria das fórmulas rurais que utiliza área A da bacia como uma variável explicativa (Simas-Hawkins, Dooge, Giandotti, Pasini e Ventura) exibe a tendência de superestimação do tempo de concentração, independente da amplitude das áreas aceitas para as fórmulas. Isto poderia indicar que a variável A não contém a mesma informação que L, pois, apesar de serem correlacionadas, A informa basicamente a magnitude e L embute informação física diretamente ligada a tempos de escoamento. A fórmula do DNOS, que usa A, L e S como variáveis explicativas, consegue, entretanto, resultados razoáveis na faixa de áreas de bacias rurais entre 25 e $400 \mathrm{~km}^{2}$, mostrando que um fator adequado de ocupação e tipo de solo pode qualificar seu desempenho.

Devem ser considerados inconclusivos os resultados obtidos com as fórmulas do SCS lag, SimasHawkins e George Ribeiro, pois houve a necessidade de fixar parâmetros sensíveis (CN para as duas primeiras e p para a última) sobre os quais não havia nenhuma informação nos arquivos-teste.

As fórmulas de tempo de concentração "urbanas" mostraram maior dificuldade de estimação 
em bacias urbanas do que as fórmulas rurais tiveram em bacias rurais. Somente três mostraram-se coerentes com as magnitudes de áreas de bacia teoricamente recomendáveis para elas, que foram as fórmulas de Schaake, Carter e Desbordes. As outras que obtiveram bons resultados, somente o conseguiram, em faixas de áreas muito restritas (fórmulas de McCuen et al e de Eagleson). Devem ser considerados , entretanto, os resultados obtidos com a fórmula de Espey-Winslow, pela incerteza em definir $\phi$ sobre o qual não havia nenhuma informação nos arquivos-teste.

Para bacias urbanas com áreas abaixo de 70 hectares a fórmula de Schaake é a mais indicada, mas é preciso considerar que ela foi ajustada a partir dos dados da maioria das bacias do arquivo-teste urbano nesta faixa de áreas. Atingindo a faixa até 51 $\mathrm{km}^{2}$, apenas a fórmula de Desbordes teve estimativas dentro do critério, mas abaixo de $11 \mathrm{~km}^{2}$, a fórmula de Carter também dá bons resultados.

Quanto à aplicação cruzada, fórmulas rurais a bacias urbanas e vice-versa, merecem algum destaque, no primeiro caso, as fórmulas de Kirpich, Corps of Engineers, Picking, DNOS e George Ribeiro, todas com resultados de razoáveis a bons, para diversas magnitudes de área. Por exemplo, a fórmula de Kirpich, freqüentemente usada nesta situação, conseguiu resultados razoáveis para bacias urbanas até $26 \mathrm{~km}^{2}$, sem que se devessem aplicar coeficientes redutores, como recomendado muitas vezes na bibliografia. Como a maioria dessas fórmulas possui variáveis explicativas convencionais (como A, L e S) parece evidente que a urbanização fica embutida nesses fatores físicos do tempo de concentração. No caso de aplicação de fórmulas urbanas a bacias rurais, o único caso relevante foi a de Eagleson, que, no entanto, não pode ser vista rigorosamente como uma fórmula genuinamente "urbana".

Em resumo, os resultados do presente artigo podem contribuir para uma melhor escolha de fórmula de tempo de concentração, fornecendo mais informações e dando indícios de que se possa validar, em alguns casos, práticas de uso que extrapolam as condições de obtenção das fórmulas. Uma recomendação de uso foi feita (Tabela 11), mas sugere-se uma consulta à Tabela 10 para uso de uma fórmula da preferência do projetista.

Justamente uma conclusão geral que se pode tirar é que as características das bacias cujos dados ajustaram as fórmulas não limitam obrigatoriamente sua aplicação. Isto foi claramente demonstrado no caso das fórmulas de parcela e fórmulas rurais de pequenas bacias (teoricamente) que fizeram boas estimativas em grandes bacias rurais. Só notaram-se dificuldades de extrapolação no caso de algumas fórmulas urbanas, que, inclusive, só desempenharam bem em faixas de áreas de bacia mais restritas que as de origem. Outro aspecto interessante, que deveria ser melhor explicado, com mais dados, é o fato das melhores estimativas de tempos de concentração em bacias rurais ocorrem com erro padrão de cerca de $20 \%$, enquanto que para bacias urbanas aproximam-se de $33 \%$. Ou seja, as fórmulas são mais precisas para bacias rurais do que para bacias urbanas.

\section{AGRADECIMENTOS}

Ao suporte dos projetos de pesquisa realizados no Instituto de Pesquisas Hidráulicas, IPH/UFRGS (Potiribu, CNPq/CT-HIDRO e Águas Urbanas IPH-URB-FINEP/CT-HIDRO) e ao grupo PUB Brasil.

\section{REFERÊNCIAS}

CANEDO, P. M., 1989, Hidrologia Superficial, In: RAMOS, F.; OCCHIPINTI, A G.; VILLA NOVA, N.A; REICHARDT, K.; CANEDO, P.M.; CLEARY, R.W.; Engenharia Hidrológica, Vol. 2, ABRH, Editora UFRJ, Rio de Janeiro

CORREIA, F. N., 1983, Métodos de análise e determinação de caudais de cheia, Tese, LNEC, Lisboa, Portugal, 380 p.

CHEN, C., WONG, T, 1990, Evaluation of resistence coefficients for overland flow analysis, Fifth International Conference on Urban Storm Drainage, Osaka, Japão, Anais, pp 1059-1064.

DAEE, 1978, Hidrologia Urbana, Primeiro Relatório Parcial, Departamento de Águas e Energia Elétrica/SP, Escola Politécnica da USP, $74 \mathrm{p}$.

DESBORDES, M., 1974, Réflexions sur les methodes de calcul des reseaux urbains d'assainissement pluvial, Thèse Docteur-Ingénieur, Université des Sciences e Techniques du Languedoc, Montpellier, França, 224 p.

GARCEZ, L. N., 1967, Hidrologia, Editora Edgard Blücher Ltda, Editora da Universidade de São Paulo, 249 p., São Paulo.

KIBLER, D. F., 1982, Desk-top Methods for Urban Stormwater Calculation, In : KIBLER, D. F. (ed.), 1982, Urban Stormwater Hydrology, American Geophysical Union, Washington DC, pp 87-135, U.S.A.

LINSLEY, R. K., KOHLER, M. A, PAULHUS, J. L. H., 1967, Hidrologia para Ingenieros, Ediciones del Castillo, Madrid.

McCUEN, R. H., WONG, S. L., RAWLS, W.J., 1984, Estimating urban time of concentration, Journal of Hydraulic 
Engineering, vol. 110, n.7, ASCE, pp 887-904

MELLO, A. J. Q., 1973, Rios e Chuvas do Brasil : Novos métodos e Tabelas de Hidrologia, Edição do Autor, Impresso Editora A M. Cavalcante Cia Ltda, Curitiba, Paraná

MOPU Tecnologia Carreteras, 1987, Cálculo hidrometeorológico de caudales máximos en pequeñas cuencas naturales, Textos de la Direccion General de Carreteras, $\mathrm{n} 12$, Espanha, $124 \mathrm{p}$.

PFAFSTETTER, O., 1976, Deflúvio Superficial, DNOS, Serviço de Divulgação, Rio de Janeiro.

PINTO, N. S.; HOLTZ, A.C.T.; MARTINS, J. A.; GOMIDE, F. L.S., 1976, Hidrologia Básica. São Paulo: Edgar Blücher, 278p.

PORTO, R.L.L., 1995, Escoamento Superficial Direto, In : TUCCI, C.E.M., PORTO, R.L.L., BARROS, M.T. (org.), 1995, Drenagem Urbana, Coleção ABRH de Recursos Hídricos, vol. 5, Editora da Universidade, Associação Brasileira de Recursos Hídricos, Porto Alegre, pp 107-165.

PRUSKY, F., SILVA, D.D., 1997, Escoamento Superficial, Caderno Didático 26, Universidade Federal de Viçosa.

RIBEIRO, G., 1955, Acerca do tempo de concentração : apenas um ensaio, Revista do Clube de Engenharia, No. 230, pp 25-31.

RIBEIRO, G., 1961, Acerca do calculo da vasão de obras d'arte : tempo de concentração, Revista do Clube de Engenharia, No. 294, pp 16-19.

SCHAAKE, J. C., GEYER, J. C., KNAPP, J. W., 1967, Experimental examination of the rational method, Journal of Hydraulics Division, ASCE, vol. 93, No. HY6, nov., pp 353-370.

SIMAS, M. J., HAWKINS, R.H., 1996, Lag time characteristics for small watersheds, www.wcc.nrcs.usda.gov/water, $7 \mathrm{p}$.

TUCCI, C. E. M., 1998. Modelos Hidrológicos, ABRH, Editora da Universidade, 1a edição, $669 \mathrm{p}$.

USDA, 1973, Linear Theory of Hydrological Systems, Technical Bulletin, United States Departement of Agriculture, No. 1468, Washington.

WANIELISTA, M.,KERSTEN, R., EAGLIN, R. , 1997, Hydro- logy, Water Quantity and Quality Control, 2a Edição, John Wiley \& Sons.

\section{Performance of Time of Concentration Formulas for Urban and Rural basins}

\section{ABSTRACT}

Time of concentration is one of the most widelyused measures of basin response for calculating design rainfalls and floods. Paradoxically, it is also a hydrological parameter that designers find difficulty in accepting as a criterion, because there is little information about applicability of the various empirical formulas that are available. Although Kibler (1982) and McCuen et al. (1984) are important references which clarify various aspects regarding origin, use and applicability of empirical formulas for concentration time, doubt and uncertainty remain concerning the absolute and comparative performance of these formulas, particularly for those in the Portuguese literature, despite groundbreaking work of Porto (1995). This situation motivated the work reported in the present paper, whose aim was to evaluate errors of 23 formulas for time of concentration, including those most commonly found in the Brazilian technical literature. It aimed to seek out whatever information was available concerning formula origin and theoretical limitations, and to assess performances of the different formulas when tested using data from urban and rural basins. Results showed that it was possible to use time-of-concentration formulas on basins whose areas were much larger than those used to calibrate them, especially under rural conditions. In the case of urban basins, the best-performing formulas for urban use showed wider error bands than the corresponding formulas for use in rural areas. The work did not seek to put all the formulas in order of rank, but to supply indicators for a basis of careful case-by-case selection.

Key-words : time of concentration, hydrograph, floods, Kirpich, urban basins, rural basins. 